\title{
How relevant is the deposition of mercury onto snowpacks? - Part 1: A statistical study on the impact of environmental factors
}

\author{
D. A. Durnford ${ }^{1}$, A. P. Dastoor ${ }^{2}$, A. O. Steen ${ }^{3, *}$, T. Berg ${ }^{3}$, A. Ryzhkov ${ }^{4}$, D. Figueras-Nieto ${ }^{2}$, L. R. Hole ${ }^{5}$, \\ K. A. Pfaffhuber ${ }^{6}$, and H. Hung ${ }^{7}$ \\ ${ }^{1}$ Independent researcher, 3031 Cedar Avenue, Montreal, QC, H3Y 1Y8, Canada \\ ${ }^{2}$ Air Quality Research Division, Environment Canada, 2121 TransCanada Highway, Dorval, QC, H9P 1J3, Canada \\ ${ }^{3}$ Norwegian University of Science and Technology, Høgskoleringen 5, 7491 Trondheim, Norway \\ ${ }^{4}$ Independent researcher, 811-4998 Maisonneuve West, Westmount, QC, H3Z 1N2, Canada \\ ${ }^{5}$ Norwegian Meteorological Institute, Allegt. 70, 5007 Bergen, Norway \\ ${ }^{6}$ Norwegian Institute for Air Research, P. O. Box 100, 2027 Kjeller, Norway \\ ${ }^{7}$ Air Quality Processes Research Section, Environment Canada, 4905 Dufferin St., Toronto, ON, M3H 5T4, Canada \\ * currently at: Norwegian Institute for Water Research, 7462 Trondheim, Norway
}

Correspondence to: A. P. Dastoor (ashu.dastoor@ec.gc.ca)

Received: 7 December 2011 - Published in Atmos. Chem. Phys. Discuss.: 5 January 2012

Revised: 14 September 2012 - Accepted: 17 September 2012 - Published: 11 October 2012

\begin{abstract}
A portion of the highly toxic methylmercury that bioaccumulates in aquatic life is created from mercury entering bodies of water with snowpack meltwater. To determine the importance of meltwater as a source of aquatic mercury, it is necessary to understand the environmental processes that govern the behavior of snowpack-related mercury. In this study we investigate relationships among 5 types of snowpack-related mercury observations and 20 model environmental variables. The observation types are the 24-h fractional loss of mercury from surface snow, and the concentrations of mercury in surface snow, seasonal snowpacks, the snowpack meltwater's ionic pulse, and long-term snowpackrelated records. The model environmental variables include those related to atmospheric mercury, insolation, wind, atmospheric stability, snowpack physical characteristics, atmospheric pressure, and solid precipitation. Bivariate and multiple linear regressions were performed twice for each mercury observation type: once with all observations, and once excluding observations from locations where the snowpack's burden of oxidizing and stabilizing halogens is known or presumed to affect snowpack mercury. Since no observations from long-term snowpack-related records were considered affected by halogens, this group of observations was included with the sets of uninfluenced observations and was not discussed with the complete, original sets of observations.
\end{abstract}

When all observations are included, only $37 \%$ of their variability can be explained, on average, with significance confidence levels averaging $81 \%$; a separate regression model predicts each mercury observation type. Without the influence of halogens, the regression models are able to explain an average of $79 \%$ of the observations' variability with significance confidence levels averaging $97 \%$. The snowpackrelated mercury observations are most strongly controlled by the dry and wet depositions of oxidized mercury, and by precipitation. Mercury deposited through wet processes is more strongly retained by snowpacks than mercury deposited through dry processes. Revolatilization of mercury deposited through wet processes may be inhibited through burial by fresh snowfalls and/or by its more central location, compared to that of mercury deposited through dry deposition, within snowpack snow grains. The two depositions of oxidized mercury together explain $84 \%$ of the variability in observed concentrations of mercury in surface snow, $52 \%$ of the variability of observed concentrations of mercury in seasonal snowpacks and their meltwater's ionic pulse, and only $20 \%$ of the variability of observed concentrations of mercury in long-term snowpack-related records; other environmental controls seemingly gain in relevance as time passes. The concentration of mercury in long-term records is apparently primarily affected by latitude; both the primary sources 
of anthropogenic mercury and the strong upper-level zonal winds are located in the midlatitudes.

\section{Introduction}

In aquatic environments, given the presence of bacteria, mercury may be methylated. Methylation occurs in freshwater wetlands (Loseto et al., 2004; Goulet et al., 2007), peatlands (Mitchell et al., 2008a), lakes (Gilmour and Henry, 1991) and oceans (Mason and Fitzgerald, 1993; Monperrus et al., 2007; Sunderland et al., 2009). Since methylmercury bioaccumulates in fish and marine mammals and is a potent neuro-toxin, it poses a serious health risk to humans. In the Arctic, where country foods include large marine mammals and fish, this issue is of great concern (Van Oostdam et al., 2005).

The source of the mercury found in the Arctic Ocean has been debated (Outridge et al., 2008). Although riverine outflow may be the dominant source of marine mercury locally (Leitch et al., 2007), it has been estimated that atmospheric deposition is the largest source of mercury in the Arctic Ocean as a whole (Outridge et al., 2008). This result is considered uncertain. An important source of the uncertainty is the lack of knowledge concerning the fate of mercury deposited onto snow-covered surfaces. The deposition of mercury onto snowpacks can be significant at high latitudes in spring as a result of Atmospheric Mercury Depletion Events (AMDEs; Schroeder et al., 1998; Lu et al., 2001; Berg et al., 2003; Ariya et al., 2004; Christensen et al., 2004; Heidam et al., 2004; Skov et al., 2004; Ferrari et al., 2005; Travnikov, 2005; Brooks et al., 2006; Kirk et al., 2006; Constant et al., 2007; Sommar et al., 2007; Johnson et al., 2008; Steffen et al., 2008). The mercury that is not revolatilized may enter the Arctic Ocean with the snowpack meltwater. To date, it is unknown what fraction of mercury is revolatilized from snowpacks. Many studies have tried to determine the fraction revolatilized (St. Louis et al., 2005, 2007; Steffen et al., 2005; Kirk et al., 2006; Brooks et al., 2008a; Hedgecock et al., 2008; Johnson et al., 2008; Outridge et al., 2008; Hirdman et al., 2009; Dommergue et al., 2010). The studies do not provide substantial reasoning as to why some locations have higher values for loss than others.

The amount of mercury that is revolatilized from snowpacks can be closely related to the amount of mercury that is deposited, as is demonstrated by Fig. 1. This figure presents observed net GEM emission at Ny-Ålesund in 2008 and the simulated deposition of oxidized mercury through both wet and dry processes. The observations are presented in Steen et al. (2009). The mercury model involved is described in Sect. 3.2.1. Figure 1 provides clear evidence that the emission of mercury from snowpacks can be directly linked to previously-deposited mercury. As this figure demonstrates, the relationship between mercury deposition and emission is often very strong both in terms of magnitude and timing, with

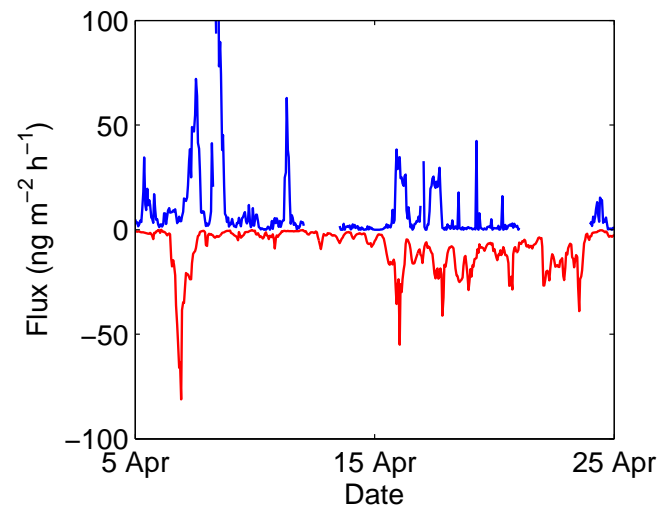

Fig. 1. Time series of net emission (blue) and deposition of oxidized mercury by both wet and dry processes (red) for Ny-Ålesund in 2008. The net emission was observed (Steen et al., 2009). The deposition of oxidized mercury was simulated by GRAHM.

deposition preceding emission slightly. However, this figure also demonstrates that the mercury deposition/emission relationship is not simple. During the first half of the time series, total emission exceeds total deposition; the revolatilization of mercury accumulated in the snowpack during polar winter (Steen et al., 2009) and/or during AMDEs earlier in the season (Steffen et al., 2005; Hirdman et al., 2009) may explain the excess emission. During the second half of the time series, total deposition appears to exceed total emission; the observation gap precludes a definitive statement. During other periods, the deposition/emission relationship is less evident.

The close relationship of Fig. 1 between the simulated deposition of oxidized mercury and the observed net emission of GEM motivated us to attempt to decipher the environmental controls that govern the fate of mercury deposited onto snowpacks. If these controls can be determined, observations of snowpack-related mercury will provide an additional constraint on atmospheric mercury models. Additional constraints are required to improve the accuracy of these models.

Prior efforts to model the fate of mercury deposited onto snowpacks include a representation by Dastoor et al. (2008) of AMDEs and their associated deposition and revolatilization in a global three-dimensional model. The representation of the processes involved was simplistic. Holmes et al. (2010), who also used a global model, constructed a snowpack reservoir to accumulate deposited mercury. The revolatilization of this mercury was based on a 180-day lifetime, which decreased to 21 days when atmospheric temperatures exceeded $270 \mathrm{~K}\left(-3^{\circ} \mathrm{C}\right)$. In addition to these global models, several small-scale process models that represent the behavior of snowpack-related mercury have been described in the literature. Both Ferrari et al. (2004) and Faïn et al. (2008) modeled the diffusion of GEM in the interstitial air of snow. Faïn et al. (2009) used a diffusion model to deduce historic atmospheric surface-level GEM concentrations from concentrations of GEM in firn air. Poulain et al. (2007b) 
constructed a mass balance for mercury in snowpacks where wet deposition, dry deposition and throughfall constituted mercury sources, while revolatilization and snowmelt constituted sinks. Values of wet deposition, revolatilization and snowmelt were calculated from observations of wet deposition and the concentration of mercury in the springtime snowpack, along with calculated rates of reduction under different canopies. The sum of dry deposition and throughfall was derived from these values and the observed snowpack mercury concentration.

Thus, to date, no one has simulated the behavior of mercury in snowpacks in anywhere near its full complexity. We undertook a three-part project to decipher the environmental controls that determine the fate of mercury deposited onto snowpacks. The first part reviewed the relevant literature, compiled datasets of observed concentrations of snowpack-related mercury, and theoretically determined the physical and chemical processes that govern the behavior of snowpack-related mercury. The results of this work are described in Durnford and Dastoor (2011).

The second part of the project consists of the present study. This study further investigates the theoreticallyderived physico-chemical controls on snowpack-related mercury by statistically exploring the relationships between environmental variables and observations of mercury in snowrelated media. No such study has ever been performed. This study further supports the development of a parameterization for the fate of mercury deposited onto snowpacks. The observations of mercury related to snowpacks that are used in the current statistical study were gathered from the literature and were presented in Durnford and Dastoor (2011) (Sect. 3.1). Five types of mercury observations were provided: the 24-h fractional loss of mercury from surface snow, and concentrations of mercury in surface snow, seasonal snowpacks, the snowpack meltwater's ionic pulse, and long-term snowpackrelated records. None of the snowpack-related mercury observations used in this statistical study are simulated. No new model development is described in the present study. However, we have used an established version of an atmospheric mercury model (Sect. 3.2.1) to provide the values of the environmental variables (Sect. 3.2.2). The 20 environmental variables used include meteorological fields, such as wind speed and precipitation, as well as mercury deposition fluxes (Sect. 3.2.2).

The third component of the project consists of the development of a snowpack/meltwater model for mercury for inclusion in large-scale atmospheric mercury models. The snowpack/meltwater model predicts the fate of mercury in snowpacks and snowpack meltwater based on mercury deposition and the local physical and chemical environments. It is based on the results of the first part of the project and the present statistical study. The snowpack/meltwater model is described and its performance evaluated in Durnford et al. (2012).

In the remainder of this article, Sect. 2 describes the chemical and physical processes that determine the fate of mercury deposited onto snowpacks. Sect. 3 describes the snowpackrelated mercury observations and the simulated environmental variables used in the study. The calculations performed are also described. In Sect. 4, the results are presented and discussed. Finally, Sect. 5 provides a summary and our conclusions.

\section{Mercury-related processes in snowpacks}

The processes affecting mercury deposited onto snowpacks depend on the mercury species involved. Gaseous elemental mercury (GEM) deposited onto snowpacks is likely revolatilized immediately given that it is highly labile (Bartels-Rausch et al., 2008). Deposited particulate mercury $(\mathrm{PHg})$ is likely retained by the snowpack given that high concentrations of mercury and particles or their proxies are often collocated (Balogh et al., 2000; Schuster et al., 2002; St. Louis et al., 2005; Cobbett et al., 2007; Loewen et al., 2007; Poulain et al., 2007a, b; Witherow and Lyons, 2008; Jitaru et al., 2009). In contrast, deposited reactive gaseous mercury (RGM) may be reduced to GEM, primarily through photoreduction by UV-B radiation in the $305-320 \mathrm{~nm}$ wavelength range (Lalonde et al., 2003; Poulain et al., 2004; St. Louis et al., 2005; Dommergue et al., 2007; Faïn et al., 2007; Johnson et al., 2008; Sherman et al., 2010). GEM is likely the only mercuric species that is emitted. Prior to revolatilization, a fraction may be reoxidized and, consequently, retained by the snowpack (Lalonde et al., 2003; Ferrari et al., 2004; Poulain et al., 2004; Mann et al., 2005; Faïn et al., 2006, 2007, 2008; Lahoutifard et al., 2006; Lin et al., 2006; Dommergue et al., 2007; Poulain et al., 2007b).

Field and laboratory studies suggest that GEM is revolatilized from the top $\sim 2$ centimeters of the snowpack (Brooks et al., 2008a; Johnson et al., 2008; Dommergue et al., 2007; Faïn et al., 2007). Prior to revolatilization, GEM molecules must be transported to the snowpack's surface. The transport is effected by molecular and turbulent diffusions (Albert and Shultz, 2002). Molecular diffusion is ubiquitous but slow (Albert and Shultz, 2002). Turbulent diffusion, or snowpack ventilation, is forced by atmospheric surface-level turbulence. This turbulence may be induced locally by wind interacting with a rough surface or by radiationally-forced thermal instability, or it may be generated elsewhere and imported (Kuhn, 2001; Albert and Shultz, 2002; Anderson and Neff, 2008).

The rates of photoreduction and revolatilization of GEM to the atmosphere increase significantly at the onset of snowmelt (Dommergue et al., 2003; Faïn et al., 2007; Sommar et al., 2007; Brooks et al., 2008b; Douglas et al., 2008). This causes a surge in the concentration of atmospheric surface-level GEM. Simultaneously, a considerable fraction of the snowpack's oxidized mercury content exits the snowpack in the meltwater's ionic pulse (Bales et al., 1990; Bishop et al., 1995; Allan et al., 2001; Kuhn, 2001; 
Lindberg et al., 2002; Dommergue et al., 2003, 2010). The ionic pulse lasts a few days (Bales et al., 1990; Bishop et al., 1995; Dommergue et al., 2003). It contains ionic concentrations that are higher than in the snowpack and that are 5-10 times higher than average meltwater concentrations (Bales et al., 1989, 1990).

The physico-chemical processes described above determine the fate of mercury in snowpacks, firn and ice (Durnford and Dastoor, 2011). The processes determining the fate of mercury in snowpack meltwater are similar. Regional variations in the behavior of snowpack-related mercury are produced by differing local environmental conditions (Durnford and Dastoor, 2011). For instance, snowpack-related halogens oxidize mercury while halides stabilize snowpack-related oxidized mercury (Lalonde et al., 2003; Ferrari et al., 2004; Faïn et al., 2006, 2008; Bartels-Rausch et al., 2011). Both the oxidation and the stabilization processes promote the retention of snowpack-related mercury. Thus, a smaller fraction of deposited mercury will be revolatilized at locations with elevated concentrations of snowpack-related halogen species.

A smaller fraction of deposited mercury will also be revolatilized at locations where the snowpack ventilation is weaker. This includes locations that experience weaker winds and/or less radiationally-induced atmospheric thermal instability (Albert and Shultz, 2002; Steffen et al., 2002; Lahoutifard et al., 2005; Steen et al., 2009; Durnford and Dastoor, 2011). Furthermore, for a given amount of atmospheric surface-level turbulence, which drives snowpack ventilation, the ventilation decreases with increasing snowpack density (Kuhn, 2001; Albert and Shultz, 2002; Domine et al., 2008).

The revolatilization of mercury from snowpacks is also seemingly reduced by the reception of fresh snow. It has been hypothesized that new snowfalls can render mercury unavailable for revolatilization by burying the previous surface layer along with its mercury content (Witherow and Lyons, 2008; Dommergue et al., 2010). As mentioned above, several studies reported that emitted GEM is sourced from only the top $\sim 2$ centimeters of the snowpack. It is possible that either the photoreduction that converts RGM to GEM within the snowpack (see above) is too weak at the former surface layer's new depth, or that the transport to the snowpack's surface of the GEM produced is too inefficient. As mentioned above, GEM is the only mercuric species emitted.

A smaller fraction of mercury is revolatilized from snowpacks under canopies than in adjacent open areas (Poulain et al., 2007b; Nelson et al., 2008). Although multiple processes contribute to this differential behavior (Fatnassi et al., 2006; Poulain et al., 2007b; Yue et al., 2008), the primary mechanism responsible for the higher retention rate in snowpacks under canopies is likely the shadowing effect (Poulain et al., 2007b). This effect reduces the amount of solar insolation reaching the surface of the snowpack. Consequently, since RGM is converted to GEM primarily through photoreduction (see above), less GEM is produced within a shaded snowpack.
At all locations, whether at mid or high latitudes, the revolatilization of mercury from snowpacks to the atmosphere depends on the difference of the GEM concentrations in the two media (Loux, 2001; Hansen et al., 2006). However, the extent of the impact of the concentration of atmospheric surface-layer GEM on this process is unknown. Furthermore, given the occurrence of high latitude AMDEs with their extremely low atmospheric surface-layer GEM concentrations (Schroeder et al., 1998; Lu et al., 2001; Bottenheim et al., 2002; Lindberg et al., 2002; Ferrari et al., 2005; Brooks et al., 2006; Kirk et al., 2006; Constant et al., 2007; Sommar et al., 2007; Steffen et al., 2008), it may be difficult to discern any general relationship between this concentration and the extent of revolatilization. In contrast, it seems highly likely, given Fig. 1 and the discussion above, that revolatilization of mercury from snowpacks increases with mercury deposition.

\section{Methodology}

\subsection{Observations}

Durnford and Dastoor (2011) presented observations of five types of snowpack-related mercury: the 24-h fractional loss of mercury from surface snow and concentrations of mercury in surface snow, seasonal snowpacks, the snowpack meltwater's ionic pulse, and long-term snowpack-related records. By definition, seasonal snowpacks do not last longer than one year. Consequently, the portion of a multi-season snowpack that was created the year prior to the current season would be classified as a long-term record. Since mercuryrelated processes occurring within the two-year old portion of a multi-season snowpack likely resemble those within seasonal snowpacks more than those within firn or ice cores, second year snowpacks are grouped with seasonal snowpacks in this study. Thus, in this study, long-term snowpack-related records consist of ice cores, firn and portions of snowpacks that are older than two years.

The datasets used in this study were compiled by Durnford and Dastoor (2011). They are based on observations from numerous field studies performed in a wide variety of polar and temperate regions, as well as the Himalayas. The reports of the field studies were published from 1978 to 2010. Thus, the datasets of snowpack-related mercury observations used in this study are not simulated. For readers wanting more information on the observations that contributed to these datasets, Durnford and Dastoor (2011) provided tables listing the sampling location, the time period involved, the sampling site and conditions (e.g., offshore/onshore, snow conditions, whether an AMDE was in progress or not, presence of a canopy), the sample size, and the mean, maximum and minimum data values. Characterizing snow conditions is not straightforward. Snowpacks consist of multiple layers of snow that are both physically and chemically different (Bales et al., 1990; King and Simpson, 2001; Sturm and Liston, 
Table 1. Mean 24-h losses of total mercury from surface snow.

\begin{tabular}{|c|c|c|c|c|c|}
\hline Location & Latitude $\left({ }^{\circ} \mathrm{N}\right)$ & Longitude $\left({ }^{\circ} \mathrm{E}\right)$ & 24-h loss $(\%)$ & $\begin{array}{l}\text { Involved in } 2 \mathrm{nd} \\
\text { set of calculations }\end{array}$ & References \\
\hline \multicolumn{6}{|c|}{ Antarctic } \\
\hline \multicolumn{6}{|c|}{ Midlatitude } \\
\hline \multicolumn{6}{|c|}{ Subarctic } \\
\hline Churchill & 58.8 & -94.1 & 51 & yes & Kirk et al. (2006) \\
\hline Kuujjuarapik/Whapmagoostui & 55.3 & -77.8 & 47 & yes & $\begin{array}{l}\text { Dommergue et al. (2003); } \\
\text { Constant et al. (2007) }\end{array}$ \\
\hline Ellesmere Island & 82.0 & -75.0 & 30 & yes & St. Louis et al. (2005) \\
\hline Ny-Ålesund & 78.9 & 11.9 & 42 & yes & $\begin{array}{l}\text { Sommar et al. (2007); } \\
\text { Dommergue et al. (2010) }\end{array}$ \\
\hline
\end{tabular}

2003; Domine et al., 2004; St. Louis et al., 2005; Beine et al., 2006; Kirk et al., 2006; Loewen et al., 2007). A small region may be characterized by a variety of snow types following the exposure of buried snowpack layers by wind action (Beine et al., 2006). Although the occurrence of AMDEs is taken into consideration in this study (Sect. 3.3), the snow conditions at the sampling site and time are not. Since this study is interested in general broad-scale relationships between environmental conditions and snowpack-related concentrations and losses of mercury, this omission is not expected to affect the robustness of the results.

At each location, a mean mercury data value was calculated from the means provided by the individual field studies gathered in Durnford and Dastoor (2011), weighted by sample size. Unspecified sample sizes were arbitrarily set to five. In all except three cases, the study where the sample size was unknown was the only study contributing to the mean value at that location; the assigning of an arbitrary sample size in these instances has absolutely no effect on the location's mean value. At Barrow, the sample size of 3 of the 12 individual mean concentrations that contribute to the mean concentration of mercury in surface snow is unknown. Also at Barrow, the sample size of 3 of the 9 individual mean concentrations that contribute to the mean concentration of mercury in seasonal snowpacks is unknown. At Churchill, the sample size of 1 of the 2 individual mean concentrations that contribute to the mean concentration of mercury in the snowpack meltwater's ionic pulse is unknown. Varying the arbitrarily chosen sample size from 5 to either 1 or 10 adjusts the mean concentration of mercury in surface snow at Barrow, in seasonal snowpacks at Barrow and in the snowpack meltwater's ionic pulse at Churchill by $\pm 2 \%\left(<1.3 \mathrm{ng} \mathrm{L}^{-1}\right)$, $\pm 25 \%\left(\sim 4 \mathrm{ng} \mathrm{L}^{-1}\right)$, and $\pm 15 \%\left(<0.75 \mathrm{ng} \mathrm{L}^{-1}\right)$, respectively. Thus, the mean concentration in seasonal snowpacks at Barrow is characterized by the greatest degree of uncertainty as a result of the unknown sample sizes. However, given the considerable range in the mean concentration of mercury in the complete dataset for seasonal snowpacks $(0.2$ to $520 \mathrm{ng} \mathrm{L}^{-1}$, median $=6.0 \mathrm{ng} \mathrm{L}^{-1}$; Table 3 ), the Barrow concentration retains its position at approximately the 75 th percentile whether the unknown sample size is assumed to be 1 or 10 . In conclusion, the assignment of a sample size of 5 in cases where the actual sample size is unknown has almost no impact on the study's results.

Since a given location's mean mercury value may represent a single observed data value or the average of mean values provided by several different field studies, with each individual mean based on multiple observations, care must be taken not to overinterpret the study's results; some locations' observed means may be more reliable than others given the disparity in the number of contributing observations. Furthermore, sampling and analysis techniques varied between the contributing field studies. The mean snowpackrelated mercury variable values calculated by Durnford and Dastoor (2011) are presented in Tables 1 through 5. The geographic distribution of these mean values is presented in Durnford and Dastoor (2011). Three long-term snowpackrelated observations are included in Table 5 but not in Durnford and Dastoor (2011). Details concerning these additional observations are presented in Table 6. In Table 6, an ice core from the ice near Mizuho Station, Antarctica was sampled by Murozumi et al. (1978), a firn core from the Dasuopu glacier 
Table 2. Mean concentrations of total mercury in surface snow.

\begin{tabular}{|c|c|c|c|c|c|}
\hline Location & Latitude $\left({ }^{\circ} \mathrm{N}\right)$ & Longitude $\left({ }^{\circ} \mathrm{E}\right)$ & $\mathrm{Hg}\left(\mathrm{ng} \mathrm{L}^{-1}\right)$ & $\begin{array}{l}\text { Involved in } 2 \text { nd } \\
\text { set of calculations }\end{array}$ & References \\
\hline \multicolumn{6}{|c|}{ Antarctic } \\
\hline McMurdo & -77.5 & 159.8 & 101.7 & no & $\begin{array}{l}\text { Sheppard et al. (1991); } \\
\text { Brooks et al. (2008b) }\end{array}$ \\
\hline \multicolumn{6}{|c|}{ Midlatitude } \\
\hline Northwestern Ontario & 49.7 & -93.7 & 1.6 & yes & $\begin{array}{l}\text { St. Louis et al. (1995); } \\
\text { Lalonde et al. (2003) }\end{array}$ \\
\hline Wisconsin & 46.0 & -89.7 & 4.1 & yes & $\begin{array}{l}\text { Bloom and Watras (1989); } \\
\text { Fitzgerald et al. (1991); } \\
\text { Lamborg et al. (1995) }\end{array}$ \\
\hline Ste Foy & 47.3 & -71.3 & 3.3 & yes & Lalonde et al. (2002) \\
\hline Maine & 44.4 & -68.3 & 9.9 & yes & Nelson et al. (2008) \\
\hline Alps & 45.3 & 5.8 & 67.6 & no & $\begin{array}{l}\text { Ferrari et al. (2002); } \\
\text { Faïn et al. (2007) }\end{array}$ \\
\hline \multicolumn{6}{|c|}{ Subarctic } \\
\hline Churchill & 58.8 & -94.1 & 36.0 & no & Kirk et al. (2006) \\
\hline Kuujjuarapik/Whapmagoostui & 55.3 & -77.8 & 10.0 & yes & $\begin{array}{l}\text { Dommergue et al. (2003); } \\
\text { Lahoutifard et al. (2006); } \\
\text { Constant et al. (2007) }\end{array}$ \\
\hline \multicolumn{6}{|c|}{ Arctic } \\
\hline Barrow & 71.3 & -156.6 & 50.6 & no & $\begin{array}{l}\text { Weiss et al. (1978); } \\
\text { Lindberg et al. (2001, 2002); } \\
\text { Brooks et al. (2006, 2008b); } \\
\text { Douglas et al. (2008); } \\
\text { Johnson et al. (2008); } \\
\text { Sherman et al. (2010) }\end{array}$ \\
\hline Ship: Arctic Ocean & 79.0 & -154.0 & 21.0 & no & Lu et al. (2001) \\
\hline Canadian Archipelago & 76.0 & -98.0 & 45.0 & no & Lu et al. (2001) \\
\hline Resolute Bay/Cornwallis Island & 74.9 & -95.0 & 3.8 & no & $\begin{array}{l}\text { Lu et al. (2001); } \\
\text { Poulain et al. (2004); } \\
\text { Lahoutifard et al. (2005); } \\
\text { Poulain et al. (2007a) }\end{array}$ \\
\hline Cornwallis, Ellesmere Islands & 78.5 & -85.0 & 30.3 & no & St. Louis et al. (2007) \\
\hline Ellesmere Island & 82.0 & -75.0 & 3.2 & yes & St. Louis et al. (2005) \\
\hline Hudson Bay/Baffin Bay/Davis Str & 66.3 & -69.7 & 55.0 & no & Lu et al. (2001) \\
\hline Labrador Sea & 57.0 & -53.0 & 38.0 & no & Lu et al. (2001) \\
\hline Summit & 72.6 & -38.5 & 0.9 & yes & Mann et al (2005) \\
\hline Ship: N Atlantic, Arctic Oceans & 83.5 & 0.0 & 3.3 & no & Aspmo et al. (2006) \\
\hline $\mathrm{Ny}-$ Ålesund & 78.9 & 11.9 & 44.5 & no & $\begin{array}{l}\text { Berg et al. (2001, 2003); } \\
\text { Ferrari et al. (2005, 2008); } \\
\text { Sommar et al. (2007); } \\
\text { Steen et al. (2009); } \\
\text { Dommergue et al. (2010); } \\
\text { Larose et al. (2010) }\end{array}$ \\
\hline
\end{tabular}

in Tibet was sampled by Wang et al. (2008), and an ice core from a glacier located at $4062 \mathrm{~m}$ a.s.l. on a saddle between the two summits of Belukha in the Siberian Altai (Olivier et al., 2003) was studied by Eyrikh et al. (2003).

In all, there are 9 mean values of the 24-h fractional loss of mercury from surface snow, 19 mean concentrations of mercury in surface snow, 20 mean concentrations of mercury in seasonal snowpacks, 8 mean concentrations of mercury in the snowpack meltwater's ionic pulse, and 8 mean concentrations of mercury in long-term snowpack-related records. Since the observations are not all from a uniform set of locations, the direct comparison of results for the different types of snowpack-related mercury observations may not be appropriate. 
Table 3. Mean concentrations of total mercury in seasonal snowpacks.

\begin{tabular}{|c|c|c|c|c|c|}
\hline Location & Latitude $\left({ }^{\circ} \mathrm{N}\right)$ & Longitude $\left({ }^{\circ} \mathrm{E}\right)$ & $\mathrm{Hg}\left(\mathrm{ng} \mathrm{L}^{-1}\right)$ & $\begin{array}{l}\text { Involved in } 2 \text { nd } \\
\text { set of calculations }\end{array}$ & References \\
\hline \multicolumn{6}{|c|}{ Antarctic } \\
\hline McMurdo & -77.5 & 159.8 & 0.2 & yes & Sheppard et al. (1991) \\
\hline McCarthy Ridge & -74.6 & 163.1 & 0.5 & yes & Capelli et al. (1998) \\
\hline Hercules Névé & -73.1 & 165.5 & 0.2 & yes & Capelli et al. (1998) \\
\hline \multicolumn{6}{|c|}{ Midlatitude } \\
\hline Tibetan Plateau & 31.5 & 90.0 & 4.5 & yes & Loewen et al. (2007) \\
\hline Idaho & 43.5 & -112.5 & 5.7 & yes & Susong et al. (2003) \\
\hline Flin Flon & 54.8 & -101.9 & 520 & no & Hicks et al. (2008) \\
\hline Minnesota & 46.0 & -94.0 & 1.0 & yes & Balogh et al. (2000) \\
\hline Northwestern Ontario & 49.7 & -93.7 & 0.6 & yes & Lalonde et al. (2003) \\
\hline North-central & 47.5 & -93.5 & 0.8 & yes & Mitchell et al. (2008b) \\
\hline Minnesota & & & & & \\
\hline Laurentians & 46.0 & -74.0 & 2.7 & yes & Poulain et al. (2007b) \\
\hline Maine & 44.4 & -68.3 & 14.0 & yes & Nelson et al. (2008) \\
\hline Alps & 45.3 & 5.8 & 130.6 & no & Faïn et al. (2007) \\
\hline \multicolumn{6}{|c|}{ Subarctic } \\
\hline Churchill & 58.8 & -94.1 & 15.7 & no & Kirk et al. (2006) \\
\hline $\begin{array}{l}\text { Kuujjuarapik/ } \\
\text { Whapmagoostui }\end{array}$ & 55.3 & -77.8 & 5.9 & yes & $\begin{array}{l}\text { Dommergue et al. (2003); } \\
\text { Constant et al. (2007) }\end{array}$ \\
\hline \multicolumn{6}{|c|}{ Arctic } \\
\hline Barrow & 71.3 & -156.6 & 17.7 & no & $\begin{array}{l}\text { Snyder-Conn et al. (1997); } \\
\text { Garbarino et al. (2002); } \\
\text { Lindberg et al. (2002); } \\
\text { Douglas et al. (2008); } \\
\text { Johnson et al. (2008) }\end{array}$ \\
\hline Cornwallis Island & 74.9 & -95.0 & 6.0 & no & Poulain et al. $(2004,2007 a)$ \\
\hline $\begin{array}{l}\text { Cornwallis, Ellesmere } \\
\text { Islands }\end{array}$ & 78.5 & -85.0 & 28.0 & no & St. Louis et al. (2007) \\
\hline Ellesmere Island & 82.0 & -75.0 & 1.1 & yes & St. Louis et al. (2005) \\
\hline Alert & 83.0 & -62.6 & 10.1 & yes & Cobbett et al. (2007) \\
\hline Ny-Ålesund & 78.9 & 11.9 & 8.5 & yes & $\begin{array}{l}\text { Ferrari et al. (2005); } \\
\text { Dommergue et al. (2010); } \\
\text { Larose et al. (2010) }\end{array}$ \\
\hline
\end{tabular}

\subsection{Model environmental variables}

\subsubsection{The model}

This study uses environmental variables simulated by Environment Canada's Global/Regional Atmospheric Heavy Metals model (GRAHM) (Dastoor and Larocque, 2004; Dastoor et al., 2008). GRAHM is an Eulerian chemical transport model built on top of EC's Global Environmental Multiscale - Global Deterministic Prediction System (GEMGDPS) weather forecasting general circulation model (Côté et al., 1998a, b). GEM-GDPS provides a single versus probabilistic ensemble forecast on a global versus regional domain.

GEM-GDPS uses a semi-Lagrangian advection scheme to promote stability, and an implicit time scheme to control high frequency oscillations. The radiative transfer scheme is based on Fouquart and Bonnel (1980) and Garand and Mailhot (1990). Stratiform precipitation is calculated by a Sundqvist-based scheme (Sundqvist, 1978). A Kain-Fritsch scheme calculates deep convective precipitation (Kain and Fritsch, 1990). The turbulent mixing of meteorological and mercury species in the boundary layer is based on turbulent kinetic energy. Both turbulent kinetic energy and cloud liquid water/ice content are prognostic model variables.

The error associated with meteorological forecasts produced by GEM-GDPS varies with the variable being forecast and the length of the forecast. In the present study, the growth of error with time is limited by the use of interconnecting forecasts (see below); the model's forecasts are tied to observations every $48 \mathrm{~h}$. Forecasts of $500-\mathrm{hPa}$ geopotential 
Table 4. Mean concentrations of total mercury in the snowpack meltwater's ionic pulse.

\begin{tabular}{|c|c|c|c|c|c|}
\hline Location & Latitude $\left({ }^{\circ} \mathrm{N}\right)$ & Longitude $\left({ }^{\circ} \mathrm{E}\right)$ & $\mathrm{Hg}\left(\operatorname{ng~L}^{-1}\right)$ & $\begin{array}{l}\text { Involved in } 2 \text { nd } \\
\text { set of calculations }\end{array}$ & References \\
\hline \multicolumn{6}{|c|}{ Midlatitude } \\
\hline Northwestern Ontario & 49.7 & -93.7 & 7.9 & yes & Allan et al. (2001) \\
\hline North-central Minnesota & 47.5 & -93.5 & 13.0 & yes & Mitchel et al. (2008b) \\
\hline Alps & 45.3 & 5.8 & 72 & no & Faïn et al. (2007) \\
\hline \multicolumn{6}{|c|}{ Subarctic } \\
\hline Churchill & 58.8 & -94.1 & 4.4 & no & Kirk et al. (2006) \\
\hline Kuujjuarapik/Whapmagoostui & 55.3 & -77.8 & 11.9 & yes & Dommergue et al. (2003) \\
\hline Svartberget Catchment & 64.2 & 19.8 & 3.5 & yes & Bishop et al. (1995) \\
\hline \multicolumn{6}{|c|}{ Arctic } \\
\hline Barrow & 71.3 & -156.6 & 21.3 & yes & $\begin{array}{l}\text { Lindberg et al. (2002); } \\
\text { Douglas et al. (2008) }\end{array}$ \\
\hline Ny-Ålesund & 78.9 & 11.9 & 6.4 & yes & Dommergue et al. (2010) \\
\hline
\end{tabular}

Table 5. Mean concentrations of total mercury in long-term snowpack-related records.

\begin{tabular}{|c|c|c|c|c|c|}
\hline Location & Latitude $\left({ }^{\circ} \mathrm{N}\right)$ & Longitude $\left({ }^{\circ} \mathrm{E}\right)$ & $\mathrm{Hg}\left(\operatorname{ng~L}^{-1}\right)$ & $\begin{array}{l}\text { Involved in } 2 \text { nd } \\
\text { set of calculations }\end{array}$ & References \\
\hline \multicolumn{6}{|c|}{ Antarctic } \\
\hline Commonwealth Glacier & -77.5 & 16.5 & 3.8 & yes & $\begin{array}{l}\text { Witherow and } \\
\text { Lyons (2008) }\end{array}$ \\
\hline Dome C & -76.0 & 124.0 & 3.7 & yes & $\begin{array}{l}\text { Vandal et al. (1993); Jitaru } \\
\text { et al. (2009) }\end{array}$ \\
\hline Mizuho Station & -70.7 & 44.3 & 1.5 & yes & Murozumi et al. (1978) \\
\hline \multicolumn{6}{|c|}{ Midlatitude } \\
\hline Dasuopu Glacier & 28.4 & 85.7 & 8.6 & yes & Wang et al. (2008) \\
\hline Upper Fremont Glacier & 43.3 & -109.4 & 7.5 & yes & Schuster et al. (2002) \\
\hline Col du Dome glacier & 45.8 & 6.8 & 2.2 & yes & Jitaru et al. (2003) \\
\hline Belukha glacier & 49.8 & 86.6 & 1.7 & yes & Eyrikh et al. (2003) \\
\hline \multicolumn{6}{|c|}{ Arctic } \\
\hline Summit & 72.6 & -38.5 & 3.3 & yes & $\begin{array}{l}\text { Boutron et al. (1998); } \\
\text { Mann et al. (2005); Faïn } \\
\text { et al. (2008) }\end{array}$ \\
\hline
\end{tabular}

heights, a basic meteorological field, are verified regularly. On an annual basis, 48-h forecasts of 500-hPa geopotential heights are characterized by a root mean square error versus North American radiosondes of $\sim 17 \mathrm{~m}$ (Environment Canada, 2012). The performance of GEM-GDPS is comparable to that of global numerical weather prediction models in operational use at major forecasting centres around the world.

Meteorological and mercury processes are fully integrated in GRAHM because at each timestep: (1) mercury emissions are added to the model mercury concentrations, (2) the meteorological processes and mercury atmospheric physico- chemical processes are simulated, (3) the mercury species are transported, and (4) mercury is deposited. The simulations of the mercuric chemical transformations and depositional processes use information calculated by the meteorological component of the model during the same timestep, including boundary layer stability and the behavior of cloud water/ice.

In GRAHM, ozone and halogens oxidize mercury in the gas phase while photochemistry and agents such as sulfur dioxide reduce mercury in the aqueous phase. Global three-dimensional monthly climatological concentrations of oxidants and reductants are used. Dry deposition is based on the resistance approach. Atmospheric Mercury Depletion 
Table 6. Mean concentrations of total mercury in long-term snowpack-related records that were not included in Durnford and Dastoor (2011).

\begin{tabular}{|c|c|c|c|c|c|c|}
\hline Location & Latitude $\left({ }^{\circ} \mathrm{N}\right)$ & Longitude $\left({ }^{\circ} \mathrm{E}\right)$ & Time period & sample size & Mean $\left(n g L^{-1}\right)$ & Reference \\
\hline Mizuho Station, Antarctica & -70.7 & 44.3 & - & 26 & 1.48 & $\begin{array}{l}\text { Murozumi et } \\
\text { al. (1978) }\end{array}$ \\
\hline \multicolumn{7}{|c|}{ Midlatitudes } \\
\hline
\end{tabular}

Events (AMDEs) are simulated in springtime at high latitudes (Dastoor et al., 2008). Simulating AMDEs involves three distinct processes: (1) mercury oxidation, which requires the simulation of spatially and temporally localized releases of oxidizing bromine species to the atmosphere during spring; (2) the transport of mercury-depleted air masses; and (3) the representation of complex, heterogeneous atmosphere/snowpack mercury fluxes. It is likely that the relative importance of these three processes varies by location and time of year.

We use the global anthropogenic mercury emission fields produced by the Arctic Monitoring and Assessment Program (AMAP) for 2005 (Pacyna et al., 2010). Non-anthropogenic oceanic and terrestrial emissions of gaseous elemental mercury are based on the global mercury budget of Mason (2009). Terrestrial non-anthropogenic emissions are divided into direct natural emissions, and emissions of previouslydeposited mercury. The former are distributed according to the natural geological enrichment of mercury. The latter are allocated according to the distribution of total deposition of mercury for historic years. The ratios of nonanthropogenic to anthropogenic emissions agree with published estimates for North America (Gbor et al., 2007) and East Asia (Shetty et al., 2008). The seasonal and diurnal variations of terrestrial emissions are based on the leaf area index and incoming direct solar radiation following Shetty et al. (2008). The impact of sea surface temperatures on oceanic emissions is implicitly represented through the use of emission values that vary by month. More explicitly, since evasion decreases with temperature (Poissant et al., 2000; Andersson et al., 2008), these emissions are zero-valued for atmospheric surface-level temperatures at or below freezing $\left(0^{\circ} \mathrm{C}\right)$. Ocean emissions also depend on the sea ice cover.

GRAHM was run over a global domain at a 1-degree horizontal resolution with 28 and 58 vertical levels before and after 31 October 2006, respectively; GRAHM's vertical resolution follows that of the host model, GEM-GDPS. The vertical resolution of GEM-GDPS was increased in 2006 as part of a technical update of the model. We performed a series of interconnecting two-day simulations, where each simulation was initialized using observed meteorological analyses from the Canadian Meteorological Centre. Mercury concentrations were passed from one simulation to the next.

In past studies, concentrations of atmospheric mercury simulated by GRAHM have been verified against observations (Ryaboshapko et al., 2007a, 2007b; Dastoor et al., 2008; Durnford et al., 2010, 2012). Concentrations estimated by GRAHM are within a factor of two of the observed concentrations. GRAHM's predicted concentrations are in good overall agreement with other mercury models (Ryaboshapko et al., 2007a, b; Travnikov et al., 2010). Unfortunately, observations of total mercury deposition are not available for model verification. Mercury deposition estimated by GRAHM is in good overall agreement with estimates from other models (Travnikov et al., 2010). However, GRAHM tends to estimate greater deposition at high latitudes, perhaps as a result of its explicit representation of AMDEs. In general, GRAHM's estimates of concentrations of atmospheric mercury and its deposition are considered to be within the observations' range of error.

\subsubsection{The environmental variables}

The 20 model environmental variables used in this study are presented in Table 7. These variables were chosen following Durnford and Dastoor (2011), who determined the physical and chemical processes that govern the behavior of snowpack-related mercury. It is hoped that these 20 variables together provide all the controls for the physical processes. Since we have multiple model variables describing different aspects of a given physical environmental characteristic, this set of 20 variables has some degree of redundancy built in. We choose to retain all 20 variables, nonetheless, in order to determine which aspect of each physical environmental characteristic is most relevant to the behavior of snowpackrelated mercury. For instance, is an average wind speed of $4 \mathrm{~m} \mathrm{~s}^{-1}$ more effective at driving snowpack ventilation than an $8 \%$ frequency of wind speeds of at least $6 \mathrm{~m} \mathrm{~s}^{-1}$ ?

The environmental variables listed in Table 7 were calculated from 6-hourly model data from 2005 through 2009. The 5-yr averaging period filters out the intra-annual variability of the environment. Accumulated variables (dry and wet depositions of oxidized mercury, and total solid 
Table 7. Model environmental variables.

\begin{tabular}{|c|c|c|c|}
\hline Number & Variable & Description & Notes \\
\hline \multicolumn{4}{|c|}{ atmospheric mercuric environment } \\
\hline 1 & GEM & concentration of surface-level atmospheric GEM & - \\
\hline 2 & DOxDp & deposition of oxidized mercury through dry processes & - \\
\hline 3 & WOxDp & deposition of oxidized mercury through wet processes & - \\
\hline \multicolumn{4}{|c|}{ variables impacting the photoreduction of oxidized mercury in snowpack-related media } \\
\hline 4 & Alb & Albedo & varies monthly \\
\hline 5 & SW & amount of short-wave radiation absorbed at the surface & - \\
\hline 6 & LAI & leaf area index & varies monthly \\
\hline \multicolumn{4}{|c|}{ variables describing atmospheric surface-level wind } \\
\hline 7 & WdSpAv & average wind speed & snowpack ventilation driven by wind pumping is \\
\hline 8 & WdSpF6 & frequency of wind speeds of at least $6 \mathrm{~m} \mathrm{~s}^{-1}$ & more effective with stronger winds \\
\hline \multicolumn{4}{|c|}{ variables describing the surface-layer atmospheric stability ${ }^{\mathrm{a}}$} \\
\hline 9 & TKE & surface-level turbulent kinetic energy & $\begin{array}{l}\text { produced by wind shear and static instability, lost } \\
\text { through viscous dissipation }\end{array}$ \\
\hline 10 & HPBL & surface stability function & based on the bulk Richardson number ${ }^{b}$ \\
\hline 11 & SfcSFn & height of the planetary boundary layer & - \\
\hline \multicolumn{4}{|c|}{ variables describing or related to the physical characteristics of the snowpack } \\
\hline 12 & SnoDp & maximum snowpack depth within a single season & - \\
\hline 13 & SnoDn & average snowpack density & - \\
\hline 14 & RH & surface-level relative humidity & - \\
\hline 15 & SfcT & surface-level temperature & - \\
\hline \multicolumn{4}{|c|}{ variables describing surface-level atmospheric pressure } \\
\hline 16 & SfcP & surface pressure $^{\mathrm{c}}$ & as pressure increases locally, skies clear. This pro- \\
\hline 17 & SLP & sea level pressure & $\begin{array}{l}\text { motes photoreduction within the snowpack, and } \\
\text { emission-augmenting radiationally-induced ther- } \\
\text { mal instability. This also diminishes the likeli- } \\
\text { hood that surface-level snowpack mercury will be } \\
\text { buried by fresh snowfalls }\end{array}$ \\
\hline \multicolumn{4}{|c|}{ variables describing solid precipitation } \\
\hline 18 & PrTot & total solid precipitation & surface-layer snowpack-related mercury can be \\
\hline 19 & PrF24h & frequency of solid precipitation of at least $0.5 \mathrm{~mm}$ over $6 \mathrm{~h}$ & rendered less available for emission by being \\
\hline 20 & PrF6h & frequency of solid precipitation of at least $5 \mathrm{~mm}$ over $24 \mathrm{~h}$ & buried by new solid precipitation \\
\hline
\end{tabular}

${ }^{\mathrm{a}}$ snowpack ventilation increases with decreasing surface-level stability; ${ }^{\mathrm{b}}$ compares the strengths of turbulence produced thermally and by vertical shear; ${ }^{\mathrm{c}}$ increases with altitude.

precipitation) represent the sum of the monthly values using the months of interest, averaged over the 5-yr period. Average variables (all variables other than accumulated variables and snow depth) are the average value of the months of interest over the 5-yr period. For all variables excluding snow depth, the months used are November through May in the Northern Hemisphere, and the corresponding months, May through November, in the Southern Hemisphere. The maximum snowpack depth within a single season represents, in the Northern Hemisphere, the five-year average of the difference between the maximum pack depth from February through June and January's depth. In the Southern Hemi- sphere, the difference between the maximum depth from August through December and July's depth is used. This process isolates a single season's contribution to multi-year snowpacks. For all variables, values are calculated separately for each hemisphere and then combined into a single global field.

\subsection{Procedure}

In this study, we are relating observations of snowpackrelated mercury to model environmental variables. Observations are valid at a single point. Model fields, however, provide average values for an entire grid cell. We 
interpolated the model fields to the observation's location using the inverse Cressman method (Cressman, 1959). Nonetheless, comparing the observation to the interpolated model value remains imperfect; observations are expected to exhibit significantly more fine-scale variability than the interpolated model values.

Determining relationships between the observations of snowpack-related mercury and the model environmental variables is also complicated by the fact that the observations were published anywhere between 1978 and 2010 (Sect. 3.1, Tables 1-5), while the model variables are based on simulations from 2005 through 2009 (Sect. 3.2.2). It is possible that concentrations of mercury in snowpack-related media have changed since the 1970s, given trends detected in observed concentrations of atmospheric mercury (Cole and Steffen, 2010; Ebinghaus et al., 2011; Slemr et al., 2011) and in wet deposition (Risch et al., 2012). However, the observed values that are used in this analysis are often based on means from multiple studies. These studies were published primarily from 2000 onwards, and mostly from 2005 onwards (Sect. 3.1, Tables 1-5). Furthermore, it is expected that mercury concentrations in snowpack-related media vary spatially considerably more than they do temporally, given the importance of local environmental conditions in determining the fate of mercury deposited onto snowpacks (Durnford and Dastoor, 2011). Thus, it is unlikely that any temporal variability in the observed snowpack-related concentrations will have a significant impact on the results of this analysis. Since this study uses mean observed values and the 5-year average (2005-2009) of simulated variables, we expect strong, low-frequency relationships between snowpack-related mercury observations and model environmental variables to be revealed.

To detect relationships between observations of snowpackrelated mercury and model environmental variables, we performed two sets of calculations. Both sets of calculations used all model environmental variables. The two sets of mercury observations used are: Set1, which contains all observed mean values available for each type of snowpackrelated mercury observation; and Set2, which contains a subset of the observed mean values available for each observation type. Tables 1 to 5 indicate which of the snowpackrelated mercury observations included in Set1 were also included in Set2. As will be discussed further below, Set1 and Set2 are identical for long-term snowpack-related mercury observations. Consequently, these observations are assigned exclusively to Set 2 . Thus, four mercury observation types are included in Set1 while five types are included in Set2.

Included in the datasets compiled by Durnford and Dastoor (2011) but excluded from both Set1 and Set2 are the observed concentrations of mercury in seasonal snowpacks and long-term snowpack-related records from studies that were conducted in Greenland and reported in the 1970s. The validity of this entire group of studies, with their tendency to report excessively high mercury concentrations, has been questioned (Jackson, 1997); both sampling procedures and analyzing techniques have improved since these studies. Additionally, Brooks et al. (2008a) reported elevated observed concentrations of mercury in surface snow and seasonal snowpacks at South Pole Station. These observations coincide with extremely high concentrations of surface-level atmospheric RGM and PHg; the mean concentrations in November-December 2003 were $344 \pm 151$ and $224 \pm 119 \mathrm{pg} \mathrm{m}^{-3}$, respectively. Given that the atmospheric concentrations are highly atypical and the snowpack concentrations are frequently outliers in scatter plots, the snowpackrelated observations at South Pole Station were also excluded from this analysis.

To create Set 2 from Set1, we subjectively removed mean values from locations where it is reasonable to believe that the snowpack contains important levels of oxidizing and stabilizing halogen species. The distribution of snowpackrelated halogens is highly heterogeneous (Garbarino et al., 2002; St. Louis et al., 2005, 2007; Constant et al., 2007; Poulain et al., 2007b). For instance, concentrations of halogens can vary dramatically between snowpacks that are only hundreds of meters apart but that are on sea ice versus land (Krnavek et al., 2012). Consequently, concentrations excluded from Set 2 include those where the sampling was performed offshore; this type of information is provided in Durnford and Dastoor (2011). Since the sites of field studies contributing to a location's observed mean can be widely distributed, and different types of observations are not always provided from the same sites, a location may be included in Set 2 for some but not all observation types. Given that we develop separate regression models for each of the five mercury observation types (Sect. 4.2.2), excluding the mean value of one or more observation types at a given location will not affect the models developed for the remaining observation types. Information on the presence of halogen species in the snowpack-related media at the sampling site was provided in some study reports. If no such information was provided, we removed from Set2 locations in coastal areas where elevated concentrations of these species are likely.

It is important to realize that snowpacks in locations experiencing AMDEs are not necessarily characterized by the high halogen contents that promote the retention of mercury within the snowpack. It is true that AMDEs are generated by halogens in the atmosphere and that AMDEs lead to significant deposition of atmospheric mercury (Schroeder et al., 1998; Lu et al., 2001; Berg et al., 2003; Ariya et al., 2004; Christensen et al., 2004; Heidam et al., 2004; Skov et al., 2004; Ferrari et al., 2005; Travnikov, 2005; Brooks et al., 2006; Kirk et al., 2006; Constant et al., 2007; Sommar et al., 2007; Johnson et al., 2008; Steffen et al., 2008). However, the oxidized mercury that is produced during AMDEs may be transported prior to deposition. There is no guarantee that the triggering atmospheric halogen species and the oxidized mercury produced are transported equally prior to deposition, given their varying atmospheric lifetimes. 
Table 8. Transformations of environmental variables.

\begin{tabular}{lccccc}
\hline Variable & 24-h loss & Surface snow & Snow packs & Melt water & Long-term records \\
\hline GEM & - & - & - & - & - \\
DOxDp & - & - & $\log$ & - & $\log$ \\
WOxDp & - & - & - & - & $\log$ \\
Alb & - & - & - & - & - \\
SW & $\log$ & $\log$ & $\log$ & $\log$ & - \\
LAI & - & - & - & - & - \\
WdSpAv & $\log$ & $\log$ & $\log$ & $\log$ & $\log$ \\
WdSpF6 & - & - & - & - & - \\
TKE & $\log$ & $\log$ & $\log$ & - & $\log$ \\
HPBL & - & - & - & - & - \\
SfcSFn & $\log$ & $\log$ & $\log$ & $\log$ & $\log$ \\
SnoDp & $\log$ & - & - & - & - \\
SnoDn & $\log$ & $\log$ & $\log$ & $\log$ & $\log$ \\
RH & $\log$ & $\log$ & $\log$ & $\log$ & $\log$ \\
SfcT & - & - & - & - & - \\
SfcP & $\log$ & $\log$ & $\log$ & $\log$ & $\log$ \\
SLP & $\log$ & $\log$ & $\log$ & $\log$ & $\log$ \\
PrTot & $\log$ & $\log$ & $\log$ & $\log$ & $\log$ \\
PrF24h & $\log$ & $\log$ & $\log$ & $\log$ & $\log$ \\
PrF6h & $\log$ & $\log$ & $\log$ & $\log$ & $\log$ \\
\hline
\end{tabular}

Similarly, a location may experience AMDEs but little or no associated deposition of oxidized mercury, given that the atmospheric lifetime of GEM is far greater than that of oxidized mercury (Constant et al., 2007; Ferrari et al., 2008). Thus, halogens and mercury associated with AMDEs are not necessarily deposited to the same locations or at the same time. Since it is the halogen content of the snowpack that is relevant to the retention of mercury within the snowpack, this differential transport and deposition is important.

Thus, although the creation of Set 2 is a subjective process, the procedure was conducted in as objective a manner as possible. It was based on the thorough literature review described in Durnford and Dastoor (2011). The difference in the results of the calculations performed for Set 1 and Set 2 indicates the importance of chemical processes in determining the behavior of snowpack-related mercury. This is an important issue.

Since no observations of long-term snowpack-related records are known or considered likely to have been influenced by snowpack-related halogens, Set 1 and Set 2 are identical for this mercury observation type. Consequently, this group of observations is included exclusively in Set2; results pertaining to mercury observations in long-term snowpackrelated records are compared only to results obtained for other sets of mercury observations included in Set2. Thus, Set1 effectively contains four mercury observation types while Set 2 contains five.

To develop models that predict snowpack-related mercury values from environmental variables, we performed bivariate linear regressions between each type of mercury observation and each model environmental variable for both Set1 and Set2. The linear regressions were performed using Matlab Version 7.13.0.564 (R2011b). Matlab returns the leastsquares solution to the system, where the sum of the squares of the residuals is minimized (Matlab, 2011). Scatter plots for each observation type and each model environmental variable were examined. Also examined were plots of the studentized residuals of the bivariate linear regressions, with error bars representing the $95 \%$ confidence interval. Both mercury observations and environmental variables were transformed as required (Table 8) to normalize the data distributions and the distributions of the residuals, and to ensure the linearity of the relationships and the homoscedasticity of the data (Belsley et al., 1980; Cook and Weisberg, 1982; Chatterjee and Hadi, 1986). Thus, the variable transformations ensure that the conditions required by a linear regression are fulfilled.

The Pearson correlation coefficient $(R)$ between each mercury observation type and each model environmental variable was calculated, as well as the Student's two-tailed tdistribution $p$-value (Matlab, 2011). A $p$-value of 0.30 indicates significance at the $70 \%$ confidence level. Model environmental variables for which the absolute value of the correlation coefficient was at least 0.35 (i.e. $|R| \geq 0.35$ ) and the $p$-value was no more than 0.30 were included in multiple linear regressions; these variables were deemed to have the potential to improve a regression model.

Several multiple linear regression models were generated for each mercury observation type. These models use different combinations of the model environmental variables that are sufficiently strongly and significantly correlated $(|R| \geq 0.35, p$-value $\leq 0.30)$ with a given observation type. A models' performance was evaluated using the coefficient 
Table 9. Results of bivariate linear regressions for Set1. Bold font indicates parameters that are sufficiently strongly $(|R| \geq 0.35)$ and significantly ( $p$-value $\leq 0.30$ ) correlated; italics indicate falsely correlated parameters.

\begin{tabular}{|c|c|c|c|c|c|c|c|c|}
\hline \multirow[t]{2}{*}{ Variable } & \multicolumn{2}{|c|}{ 24-h loss } & \multicolumn{2}{|c|}{ Surface snow } & \multicolumn{2}{|c|}{ Snowpacks } & \multicolumn{2}{|c|}{ Meltwater } \\
\hline & $R$ & $p$-value & $R$ & $p$-value & $R$ & $p$-value & $R$ & $p$-value \\
\hline GEM & 0.19 & 0.62 & -0.38 & 0.11 & 0.45 & 0.05 & 0.25 & 0.55 \\
\hline DOxDp & 0.45 & 0.22 & 0.12 & 0.62 & 0.30 & 0.20 & -0.03 & 0.94 \\
\hline WOxDp & 0.21 & 0.58 & 0.11 & 0.66 & 0.40 & 0.08 & 0.31 & 0.46 \\
\hline Alb & -0.26 & 0.50 & 0.12 & 0.64 & -0.31 & 0.19 & 0.05 & 0.90 \\
\hline SW & 0.37 & 0.33 & -0.12 & 0.61 & 0.23 & 0.33 & 0.14 & 0.74 \\
\hline LAI & 0.29 & 0.45 & -0.31 & 0.20 & 0.23 & 0.32 & -0.48 & 0.23 \\
\hline WdSpAv & -0.22 & 0.56 & 0.18 & 0.45 & -0.43 & 0.06 & 0.04 & 0.93 \\
\hline WdSpF6 & 0.15 & 0.70 & 0.16 & 0.51 & -0.38 & 0.10 & -0.43 & 0.29 \\
\hline TKE & 0.22 & 0.58 & -0.20 & 0.42 & 0.21 & 0.38 & -0.13 & 0.76 \\
\hline HPBL & 0.24 & 0.54 & -0.11 & 0.67 & 0.30 & 0.19 & 0.34 & 0.42 \\
\hline SfcSFn & -0.34 & 0.38 & -0.10 & 0.69 & -0.16 & 0.50 & 0.75 & 0.03 \\
\hline SnoDp & -0.09 & 0.82 & -0.05 & 0.85 & 0.20 & 0.40 & 0.29 & 0.49 \\
\hline SnoDn & -0.05 & 0.89 & 0.13 & 0.60 & 0.20 & 0.39 & -0.25 & 0.56 \\
\hline RH & 0.15 & 0.70 & -0.10 & 0.70 & 0.43 & 0.06 & 0.21 & 0.61 \\
\hline SfcT & 0.26 & 0.49 & -0.06 & 0.82 & 0.38 & 0.09 & 0.19 & 0.65 \\
\hline SfcP & 0.30 & 0.43 & 0.25 & 0.31 & 0.24 & 0.32 & -0.73 & 0.04 \\
\hline SLP & 0.07 & 0.86 & -0.47 & 0.04 & 0.54 & 0.01 & 0.41 & 0.32 \\
\hline PrTot & 0.29 & 0.45 & -0.07 & 0.77 & 0.29 & 0.21 & 0.31 & 0.46 \\
\hline PrF24h & 0.16 & 0.71 & -0.29 & 0.27 & 0.24 & 0.34 & 0.06 & 0.89 \\
\hline PrF6h & 0.28 & 0.47 & -0.03 & 0.89 & 0.19 & 0.41 & -0.04 & 0.93 \\
\hline Average of values in bold & 0.45 & 0.22 & 0.38 & 0.12 & 0.43 & 0.07 & 0.60 & 0.15 \\
\hline
\end{tabular}

of determination $\left(R^{2}\right)$, which indicates how much of the observations' variability is explained by the model, and the Fstatistic $p$-value (Matlab, 2011). The statistics evaluate the extent to which the ensemble of environmental variables that participate in a multiple linear regression controls the processes that determine the observed mercury values. Lower $R^{2}$ values and/or higher $p$-values suggest that the environmental control of at least one process that is important in determining the value of the mercury variable was omitted from the regression. Since locations where snowpacks are known or deemed likely to contain halogens were excluded from Set 2 , it is known a priori that models generated for Set 2 do not include the environmental control of the oxidation and stabilization of mercury in snowpacks by halogens; the models generated for Set2 are not applicable for snowpacks containing halogens.

Although models that are highly successful at predicting the observed values are characterized by $R^{2}$ values approaching unity, a high $R^{2}$ value may also indicate that over-fitting has occurred. An over-fitted model has learnt how to memorize the observed values rather than understanding the general relationships involved (Babyak, 2004). The high $R^{2}$ obtained is meaningless, as the model will not necessarily perform well when applied to other situations. Over-fitting can be expected when at least $n / 2$ environmental variables are used in a regression with $n$ observations (Babyak, 2004). Using $n-1$ environmental variables for $n$ observations is an extreme case of over-fitting.
A further concern are false colinearities. A scatter plot that contains a closely clustered group of observations and a single outlier located at a distance exemplifies a false colinearity. The correlation coefficient for such a distribution is high but misleading; the predictor, or model environment variable, is not, in reality, able to predict the predictand, or mercury value.

A final concern is the interdependence of the environmental variables involved in a multiple linear regression. To ensure the independence of the participating environmental variables, some of the models generated, including the "best" models for Set2, use at most one variable per environmental variable category (Tables 12, 13), e.g. only one of the three solid precipitation variables (PrTot, PrF24h, PrF6h). The depositions of oxidized mercury through dry and wet processes are not considered interdependent. Wet deposition can increase with increasing precipitation in a given region despite decreasing mercury concentrations in precipitation (Risch et al., 2012). In contrast, dry deposition is continuous, even during precipitation events (Lin et al., 2006). Moreover, if the two deposition variables were linearly dependent, one of them would be assigned a zero-valued coefficient by Matlab (Matlab, 2011). 

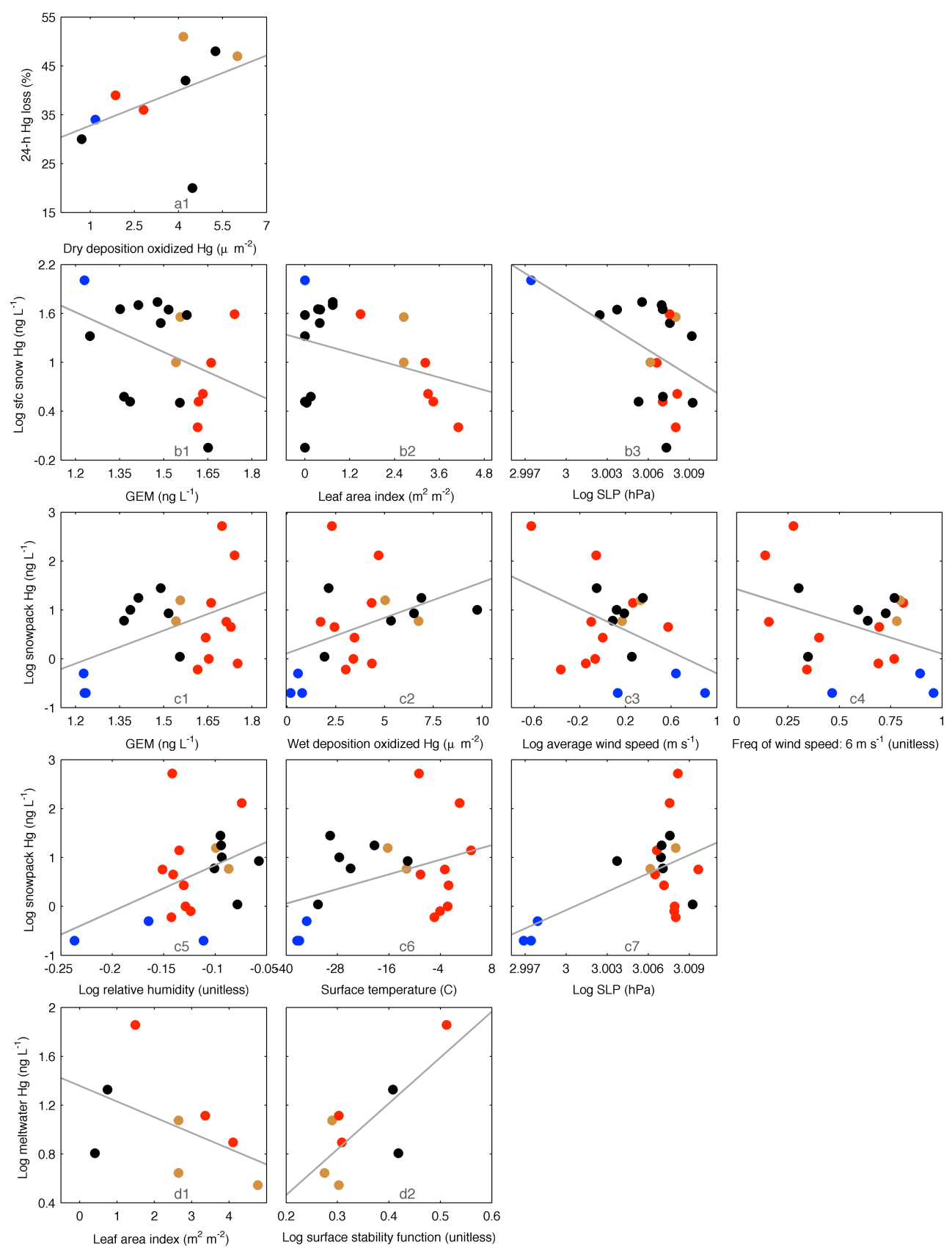

Fig. 2. Scatter plots of model environmental variables that are sufficiently strongly and significantly correlated with Set1: (a1) 24-h fractional loss of mercury from surface snow, and concentrations of mercury in (b1-b3) surface snow, (c1-c7) seasonal snowpacks, and (d1-d2) the snowpack meltwater's ionic pulse. Blue, red, brown, and black circles represent observations from, respectively, Antarctica, midlatitudes, the subarctic and the Arctic. The grey line was estimated by the bivariate linear regression for Set1.

\section{Results and discussion}

\subsection{Set1}

\subsubsection{Bivariate linear regressions}

Table 9 presents correlation coefficients and significance confidence levels for the snowpack-related mercury obser- vations from Set1 and the model environmental variables. Set1 includes all observations (Sect. 3.3). Variables for which the absolute value of the coefficient is at least 0.35 $(|R| \geq 0.35)$ and the relationship is significant at least the $70 \%$ confidence level ( $p$-value $\leq 0.30)$ are in bold font; these are the environmental variables that are considered sufficiently strongly and significantly correlated with the 
Table 10. Multiple linear regression models for Set1.

\begin{tabular}{lll}
\hline Observation type & $R^{2}$ & $p$-value \\
\hline 24-h loss & 0.21 & 0.22 \\
Surface snow & 0.27 & 0.08 \\
Snowpacks & 0.42 & 0.36 \\
Meltwater & 0.57 & 0.12 \\
\hline
\end{tabular}

indicatedmercury observation to be included in the multiple linear regression for that specific mercury observation.

The environmental variables have been transformed to promote the normalcy of their distributions (Sect. 3.3). The transformation performed for a given environmental variable is identical in all calculations conducted in association with a given mercury observation type. The nature of these transformations is indicated in Table 8. For the sake of brevity, this information has not been repeated in Tables 9, 11-12.

In Table 9, the average $|R|$ and the average $p$-value over all sufficiently strongly and significantly correlated (hereafter "correlated") model environment variables is provided for each observation type. No average $|R|$ value is higher than 0.45 except that of the meltwater's ionic pulse $(|R|=0.62)$. Encouragingly, the two environmental variables that are correlated with the meltwater's ionic pulse are, on are, on average, significant at the $87 \%$ confidence level. However, two correlated model environmental variables are considered falsely correlated with the meltwater mercury concentrations (Fig. 2; Sect. 3.3). These variables, which are italicized in Table 9, were excluded from the calculations of $|R|$ and the average $p$-value and do not participate in the multiple linear regression performed for Set 1 for this mercury concentration. The overall weakness of the results for Set1 is surprising given that, theoretically, a single set of physical and chemical processes governs the behavior of snowpack-related mercury at all locations (Durnford and Dastoor, 2011); one would expect the general nature of these processes to yield stronger relationships.

Another disappointing result is the fact that the collections of correlated model environmental variables listed in Table 9 and shown in Fig. 2 are often unrealistic. For instance, the 24-h fractional loss of mercury from surface snow is supposedly related only to the dry deposition of oxidized mercury (DOxDp). This suggestion that the environment has no impact on revolatilization contradicts the heterogeneity of the fractional loss. Also unrealistic is the result that the concentration of mercury in surface snow is supposedly related only to the concentration of surface-level atmospheric GEM (GEM), the leaf area index (LAI) and sea level pressure (SLP). In contrast, the dependence of the concentration of mercury in seasonal snowpacks on atmospheric GEM (GEM), wet deposition of oxidized mercury (WOxDp), wind speed (WdSpAv, WdSpF6), relative humidity $(\mathrm{RH})$, surface temperature (SfcT) and sea level pressure (SLP) is realistic.
Interestingly, the concentration of mercury in the meltwater's ionic pulse, for which the average $|R|$ is by far the highest (Table 9), is supposedly unrelated both to the concentration of atmospheric GEM (GEM) and to the deposition of oxidized mercury (DOxDp, WOxDp). It seems unrealistic that the concentration of mercury in meltwater be completely independent of all sources of mercury.

\subsubsection{Multiple linear regressions}

The four multiple linear regression models for Set 1 are able to explain an average of $37 \%$ of the mercury observations' variability (Table 10) with a confidence level of $81 \%$ for the significance. The regressions include all model environmental variables that are correlated with the mercury observation type in question; a separate regression model is developed for each mercury observation type. Given the generally low correlations of Table 9, the poor performances of these regression models are not surprising. Exceptionally, the model for the concentration of mercury in the snowpack meltwater's ionic pulse is able to explain $57 \%$ of the mercury concentration's variability and is significant at the $88 \%$ confidence level. Thus, both the bivariate and multiple linear regressions for the concentration of mercury in the snowpack meltwater's ionic pulse produce encouraging results mathematically. However, this regression model seems unlikely to perform well at other locations, given that no mercuryrelated environmental variable is included. Therefore, none of the regression models for Set1 is expected to predict mercury observations accurately at new locations. As discussed in Sect. 3.3, this likely indicates that the environmental control of at least one process that is important in determining the value of the mercury observation type being predicted was not included in the regression model.

\subsection{Set2}

\subsubsection{Bivariate linear regressions}

For each type of snowpack-related mercury observation that participates in both Set1 and Set2, the correlated model environmental variables are more strongly correlated, on average, in Set2 than in Set1 (Table 11). As mentioned in Sect. 3.3, the concentrations of mercury in long-term snowpack-related records participate in Set2 alone. The greatest increases in average correlation are found for the concentration of mercury in surface snow ( 0.38 to 0.66$)$ and the 24 -h fractional loss of mercury from surface snow $(0.45$ to 0.70$)$. However, the confidence level of the significance of these correlations increases, on average, only for the 24-h fractional loss of mercury from surface snow ( $p$-value decreases from 0.22 to 0.10 ); it remains virtually unchanged for the remaining observation types. The correlated model environmental variables that are deemed to be falsely correlated with a given mercury observation type (Sect. 3.3) are italicized in 
Table 11. Results of bivariate linear regressions for Set 2 . Bold font indicates parameters that are sufficiently strongly ( $R \mid \geq 0.35)$ and significantly ( $p$-value $\leq 0.30$ ) correlated; italics indicate falsely correlated parameters.

\begin{tabular}{|c|c|c|c|c|c|c|c|c|c|c|}
\hline \multirow[t]{2}{*}{ Variable } & \multicolumn{2}{|c|}{ 24-h loss } & \multicolumn{2}{|c|}{ Surface snow } & \multicolumn{2}{|c|}{ Snowpacks } & \multicolumn{2}{|c|}{ Meltwater } & \multicolumn{2}{|c|}{ Long-term } \\
\hline & $R$ & $p$-value & $R$ & $p$-value & $R$ & $p$-value & $R$ & $p$-value & $R$ & $p$-value \\
\hline GEM & 0.05 & 0.91 & -0.29 & 0.53 & 0.50 & 0.07 & -0.36 & 0.48 & 0.13 & 0.75 \\
\hline DOxDp & 0.88 & 0.00 & 0.75 & 0.05 & 0.52 & 0.06 & 0.60 & 0.21 & 0.23 & 0.59 \\
\hline WOxDp & 0.77 & 0.03 & 0.85 & 0.02 & 0.71 & 0.01 & 0.66 & 0.16 & 0.18 & 0.67 \\
\hline $\mathrm{Alb}$ & -0.05 & 0.91 & -0.44 & 0.32 & -0.41 & 0.15 & 0.63 & 0.19 & -0.19 & 0.65 \\
\hline SW & 0.19 & 0.65 & 0.50 & 0.26 & 0.33 & 0.25 & -0.29 & 0.58 & 0.44 & 0.28 \\
\hline LAI & 0.22 & 0.60 & 0.38 & 0.41 & 0.14 & 0.64 & -0.50 & 0.31 & 0.25 & 0.54 \\
\hline WdSpAv & -0.16 & 0.70 & 0.05 & 0.91 & -0.17 & 0.57 & 0.54 & 0.27 & -0.22 & 0.60 \\
\hline WdSpF6 & 0.44 & 0.28 & 0.23 & 0.62 & -0.07 & 0.81 & 0.62 & 0.19 & -0.09 & 0.83 \\
\hline TKE & 0.07 & 0.87 & 0.37 & 0.41 & 0.35 & 0.22 & -0.66 & 0.15 & 0.12 & 0.78 \\
\hline HPBL & 0.22 & 0.61 & 0.37 & 0.42 & 0.32 & 0.27 & -0.23 & 0.67 & 0.11 & 0.79 \\
\hline SfcSFn & -0.52 & 0.19 & -0.43 & 0.34 & -0.32 & 0.27 & 0.24 & 0.65 & 0.18 & 0.67 \\
\hline SnoDp & -0.16 & 0.71 & -0.14 & 0.77 & 0.07 & 0.80 & -0.39 & 0.45 & -0.09 & 0.84 \\
\hline SnoDn & 0.05 & 0.90 & 0.34 & 0.45 & 0.35 & 0.23 & 0.37 & 0.47 & 0.33 & 0.43 \\
\hline RH & 0.35 & 0.40 & -0.02 & 0.97 & 0.49 & 0.08 & -0.11 & 0.83 & 0.05 & 0.91 \\
\hline SfcT & 0.34 & 0.41 & 0.54 & 0.21 & 0.55 & 0.04 & -0.72 & 0.11 & 0.20 & 0.64 \\
\hline $\mathrm{SfcP}$ & 0.72 & 0.05 & 0.77 & 0.05 & 0.17 & 0.57 & 0.32 & 0.53 & -0.47 & 0.24 \\
\hline SLP & 0.21 & 0.62 & -0.46 & 0.30 & 0.57 & 0.03 & 0.65 & 0.16 & 0.26 & 0.54 \\
\hline PrTot & 0.28 & 0.51 & 0.43 & 0.33 & 0.54 & 0.05 & -0.74 & 0.09 & 0.01 & 0.98 \\
\hline PrF24h & -0.06 & 0.90 & -0.03 & 0.96 & 0.43 & 0.14 & -0.78 & 0.07 & 0.27 & 0.66 \\
\hline PrF6h & 0.32 & 0.44 & 0.32 & 0.49 & 0.40 & 0.15 & -0.70 & 0.12 & 0.00 & 0.99 \\
\hline Average of values in bold & 0.70 & 0.10 & 0.66 & 0.13 & 0.51 & 0.08 & 0.67 & 0.15 & 0.46 & 0.26 \\
\hline
\end{tabular}

Table 11. These environmental variables were excluded from the calculations of $|R|$ and the average $p$-value and do not participate in any multiple linear regressions performed for Set2.

The number of model environmental variables that are correlated increases for Set 2 over Set 1 for all four mercury observation types participating in both Set1 and Set2. The greatest gain in the number of correlated environmental variables is associated with the snowpack meltwater's ionic pulse (2 to 10). The remaining observation types gain at most two additional correlated environmental variables.

Considering the identities of the model environmental variables that are correlated with the 24-h fractional loss of mercury from surface snow in Set2, the fractional loss is found to increase with the deposition of oxidized mercury through both dry (DOxDp) and wet (WOxDp) processes (Table 11). Moreover, these relationships are significant at a greater than $95 \%$ confidence level. This is as one might expect. The black outlier in the deposition scatter plots (Fig. 3a, b) represents Barrow. The halogen content of the snowpacks near Barrow can be extremely high (Garbarino et al., 2002). This hints at the role of halogens in decreasing the revolatilization of mercury from coastal or sea ice-based snowpacks. The 24-h fractional loss of mercury from surface snow also increases with the frequency of wind speeds of at least $6 \mathrm{~m} \mathrm{~s}^{-1}(\mathrm{WdSpF} 6)$. This agrees with Albert and Shultz (2002), Steffen et al. (2002), Lahoutifard et al. (2005) and Steen et al. (2009) who found that wind speed signif- icantly affects mercury revolatilization. However, this relationship is significant at only the $70 \%$ confidence level. This lesser significance likely reflects the fact that revolatilization is effected not only by turbulent diffusion, which is related to wind speeds, but also by molecular diffusion, which is not (Sect. 2). Thus, these results are realistic.

The relationships between the concentration of mercury in surface snow and its correlated model environmental variables are more difficult to interpret; the only transparent relationships are the increase in this type of mercury concentration with increasing dry (DOxDp) and wet (WOxDp) depositions of oxidized mercury. Not surprisingly, these relationships are significant at at least the $95 \%$ confidence level (Table 11, Fig. 4). However, revolatilization is expected to increase with photoreduction and, consequently, the amount of short-wave radiation absorbed at the surface (SW) (Sect. 2). Thus, the positive correlation of short-wave radiation with the concentration of mercury in surface snow is surprising. Similarly, given the fact that increasing atmospheric temperatures reduce atmospheric stability, thereby promoting revolatilization (Sect. 2), the positive correlation of temperature with the concentration of mercury in surface snow is unexpected. Interestingly, the scatter plots suggest that if the two arctic data points were removed from the regressions for short-wave radiation and atmospheric temperature, both these variables would be poor predictors of this mercury concentration (Fig. 4). 
Table 12. Multiple linear regression models for Set2. Bold font indicates the best model for each mercury observation type.

\begin{tabular}{|c|c|c|c|c|}
\hline Model & Rationale & $R^{2}$ & $p$-value & Variables \\
\hline \multicolumn{5}{|c|}{ 24-h fractional loss of mercury from surface snow } \\
\hline 1 & $\begin{array}{l}\text { All sufficiently strongly and significantly corre- } \\
\text { lated variables }\end{array}$ & 0.78 & 0.08 & DOxDp, WOxDp, WdSpF6 \\
\hline 2 & Use the most readily obtainable variables & 0.71 & 0.05 & WOxDp, WdSpF6 \\
\hline 3 & $\begin{array}{l}\text { Use variables significant at the } 85 \% \text { confidence } \\
\text { level }\end{array}$ & 0.77 & 0.03 & DOxDp, WOxDp \\
\hline 4 & $\begin{array}{l}\text { Use variables significant at the } 95 \% \text { confidence } \\
\text { level }\end{array}$ & 0.77 & 0.03 & DOxDp, WOxDp \\
\hline 5 & Dry and wet mercury depositions alone & 0.77 & $\mathbf{0 . 0 3}$ & DOxDp, WOxDp \\
\hline \multicolumn{5}{|c|}{ Concentration of mercury in surface snow } \\
\hline 6 & $\begin{array}{l}\text { All sufficiently strongly and significantly corre- } \\
\text { lated variables }\end{array}$ & 0.92 & 0.15 & DOxDp, WOxDp, SW, SfcT \\
\hline 7 & Use the most readily obtainable variables & 0.77 & 0.17 & WOxDp, SW, SfcT \\
\hline 8 & $\begin{array}{l}\text { Use variables significant at the } 85 \% \text { confidence } \\
\text { level }\end{array}$ & 0.84 & 0.03 & DOxDp, WOxDp \\
\hline 9 & $\begin{array}{l}\text { Use variables significant at the } 95 \% \text { confidence } \\
\text { level }\end{array}$ & 0.84 & 0.03 & DOxDp, WOxDp \\
\hline 10 & Dry and wet mercury depositions alone & 0.84 & $\mathbf{0 . 0 3}$ & DOxDp, WOxDp \\
\hline 11 & Test the impact of SW & 0.87 & 0.08 & DOxDp, WOxDp, SW \\
\hline 12 & Test the impact of SfcT & 0.86 & 0.08 & DOxDp, WOxDp, SfcT \\
\hline \multicolumn{5}{|c|}{ Concentration of mercury in seasonal snowpacks } \\
\hline 13 & $\begin{array}{l}\text { All sufficiently strongly and significantly corre- } \\
\text { lated variables }\end{array}$ & 0.97 & 0.03 & $\begin{array}{l}\text { GEM, DOxDp, WOxDp, Alb, RH, SfcT, PrTot, } \\
\text { PrF24h, PrF6h }\end{array}$ \\
\hline 14 & Use the most readily obtainable variables & 0.69 & 0.31 & $\begin{array}{l}\text { GEM, WOxDp, RH, SfcT, PrTot, PrF } 24 h \text {, } \\
\text { PrF6h }\end{array}$ \\
\hline 15 & $\begin{array}{l}\text { Use variables significant at the } 85 \% \text { confidence } \\
\text { level }\end{array}$ & 0.84 & 0.09 & $\begin{array}{l}\text { GEM, DOxDp, WOxDp, RH, SfcT, PrTot, } \\
\text { PrF24h }\end{array}$ \\
\hline 16 & $\begin{array}{l}\text { Use variables significant at the } 95 \% \text { confidence } \\
\text { level }\end{array}$ & 0.64 & 0.02 & WOxDp, SfcT, PrTot \\
\hline 17 & Dry and wet mercury depositions alone & 0.51 & 0.02 & DOxDp, WOxDp \\
\hline 18 & Test the impact of DOxDp versus WOxDp & 0.39 & 0.17 & DOxDp, SfcT, PrTot \\
\hline 19 & Test the impact of DOxDp as well as WOxDp & 0.79 & 0.00 & DOxDp, WOxDp, SfcT, PrTot \\
\hline 20 & Test the impact of GEM & 0.79 & 0.01 & GEM, DOxDp, WOxDp, SfcT, PrTot \\
\hline 21 & Test the impact of Alb & 0.82 & 0.01 & DOxDp, WOxDp, Alb, SfcT, PrTot \\
\hline 22 & Test the impact of RH & 0.80 & 0.01 & DOxDp, WOxDp, RH, SfcT, PrTot \\
\hline 23 & Test the impact of PrF24h & 0.78 & 0.00 & DOxDp, WOxDp, SfcT, PrF24h \\
\hline 24 & Test the impact of PrF6h & 0.78 & 0.01 & DOxDp, WOxDp, SfcT, PrF6h \\
\hline 25 & Test the impact of SfcT & 0.66 & 0.01 & DOxDp, WOxDp, PrTot \\
\hline \multicolumn{5}{|c|}{ Concentration of mercury in the snowpack meltwater's ionic pulse } \\
\hline 26 & $\begin{array}{l}\text { All sufficiently strongly and significantly corre- } \\
\text { lated variables }\end{array}$ & 1.00 & $-*$ & $\begin{array}{l}\text { DOxDp, WOxDp, Alb, WdSpAv, WdSpF6, } \\
\text { TKE, SfcT, PrTot, PrF24h, PrF6h }\end{array}$ \\
\hline 27 & Use the most readily obtainable variables & 1.00 & $-^{*}$ & $\begin{array}{l}\text { WOxDp, WdSpAv, WdSpF6, SfcT, PrTot, } \\
\text { PrF24h, PrF6h }\end{array}$ \\
\hline 28 & $\begin{array}{l}\text { Use variables significant at the } 85 \% \text { confidence } \\
\text { level }\end{array}$ & 0.77 & 0.66 & SfcT, PrTot, PrF24h, PrF6h \\
\hline 29 & $\begin{array}{l}\text { Use variables significant at the } 95 \% \text { confidence } \\
\text { level }\end{array}$ & - & - & None available \\
\hline 30 & Dry and wet mercury depositions alone & 0.52 & 0.33 & DOxDp, WOxDp \\
\hline 31 & Test the impact of Alb & 0.43 & 0.43 & WOxDp, Alb \\
\hline 32 & Test the impact of WdSpF6 & 0.43 & 0.43 & WOxDp, WdSpF6 \\
\hline 33 & Test the impact of TKE & 0.45 & 0.41 & WOxDp, TKE \\
\hline
\end{tabular}


Table 12. Continued.

\begin{tabular}{|c|c|c|c|c|}
\hline Model & Rationale & $R^{2}$ & $p$-value & Variables \\
\hline 34 & Test the impact of SfcT & 0.52 & 0.34 & WOxDp, SfcT \\
\hline 35 & Test the impact of PrTot & 0.84 & 0.06 & WOxDp, PrTot \\
\hline 36 & Test the impact of PrF24h & 0.75 & 0.13 & WOxDp, PrF24h \\
\hline 37 & Test the impact of PrF6h & 0.86 & 0.05 & WOxDp, PrF6h \\
\hline \multicolumn{5}{|c|}{ Concentration of mercury in long-term snowpack-related records } \\
\hline 38 & $\begin{array}{l}\text { All sufficiently strongly and significantly cor- } \\
\text { related variables }\end{array}$ & 0.70 & 0.05 & SW, SfcP \\
\hline 39 & Use the most readily obtainable variables & 0.70 & 0.05 & $\mathrm{SW}, \mathrm{SfcP}$ \\
\hline 40 & $\begin{array}{l}\text { Use variables significant at the } 85 \% \text { confidence } \\
\text { level }\end{array}$ & - & - & None available \\
\hline 41 & $\begin{array}{l}\text { Use variables significant at the } 95 \% \text { confidence } \\
\text { level }\end{array}$ & - & - & None available \\
\hline 42 & Dry and wet mercury depositions alone & 0.20 & 0.58 & DOxDp, WOxDp \\
\hline
\end{tabular}

* Too many model environmental variables for the number of mercury observations for a $p$-value to be calculated.

Table 13. Best multiple linear regression models for Set2.

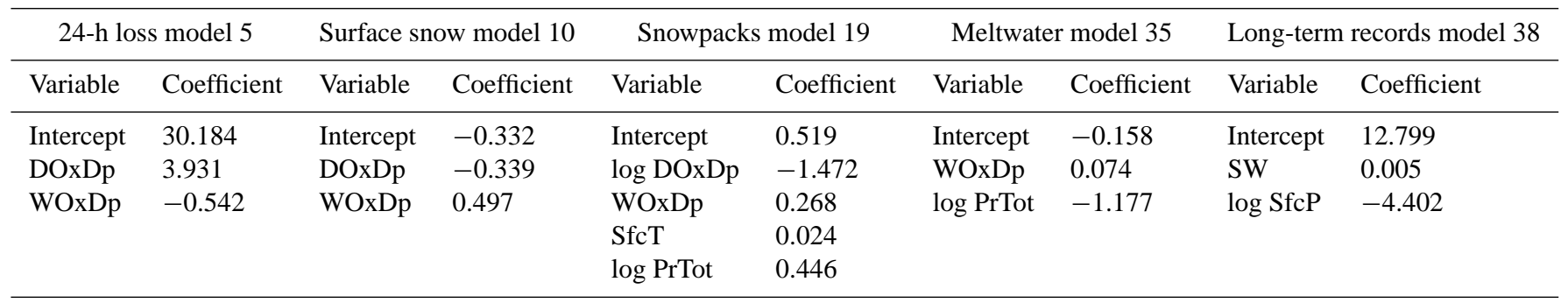

The concentration of mercury in seasonal snowpacks is positively correlated with dry (DOxDp) and wet (WOxDp) depositions of oxidized mercury (Table 11, Fig. 5). This is expected. Moreover, both relationships are significant at a greater than $90 \%$ confidence level. Since increasing the concentration of atmospheric GEM (GEM) both suppresses revolatilization and promotes deposition (Lin et al., 2006; Loux, 2001; Hansen et al., 2006), the positive correlation between the concentration of mercury in seasonal snowpacks and atmospheric GEM is reasonable. Given the importance of wet deposition $(R=0.71, p$-value $=0.01)$, the positive correlations with the three precipitation variables (PrTot, PrF24h, PrF6h) are also reasonable. Interestingly, total precipitation is not only the most strongly correlated of these three variable ( $R=0.54$ versus $\sim 0.40$ ) but its relationship is also significant at a higher level of confidence $(95 \%$ versus $\sim 85 \%$ ). The relationship between precipitation, wet deposition and snowpack-related concentrations of mercury will be discussed further below. The positive correlation with relative humidity $(\mathrm{RH})$ reinforces the importance of precipitation in controlling the concentration of mercury in seasonal snowpacks. However, as per the concentration of mercury in surface snow, the concentration of mercury in seasonal snowpacks is unexpectedly negatively correlated with albedo (Alb) and positively correlated with surface temperature (SfcT). The scatter plots for albedo and surface temperature (Fig. 5) indicate that the three Antarctic concentrations are largely responsible for the sign of these two correlations.

As per the concentration of mercury in seasonal snowpacks, the concentration of mercury in the meltwater's ionic pulse is correlated with the two depositions of oxidized mercury (DOxDp, WOxDp) and the three precipitation variables (PrTot, PrF24h, PrF6h) (Table 11, Fig. 6). However, the significance of the two deposition variables has decreased to confidence levels of $\sim 80 \%$ while the correlations of the precipitation variables have become negative. This sign reversal may indicate that the generation of the ionic pulse (Bales et al., 1989, 1990; Kuhn, 2001; Bishop et al., 1995; Allan et al., 2001; Lindberg et al., 2002; Dommergue et al., 2003, 2010) is variable; the snowpack meltwater's ionic pulse may be weaker, i.e. more dilute, in a deeper snowpack. No evidence is available to prove or disprove this hypothesis. However, it seems quite reasonable to expect that deeper snowpacks take longer to become isothermal and that the lower layers of a deeper snowpack do not respond as readily to atmospheric temperature fluctuations; it is likely that fewer melt-freeze cycles occur in deeper snowpacks. Melt-freeze cycles likely allow the mercury to be increasingly pooled at the base of 

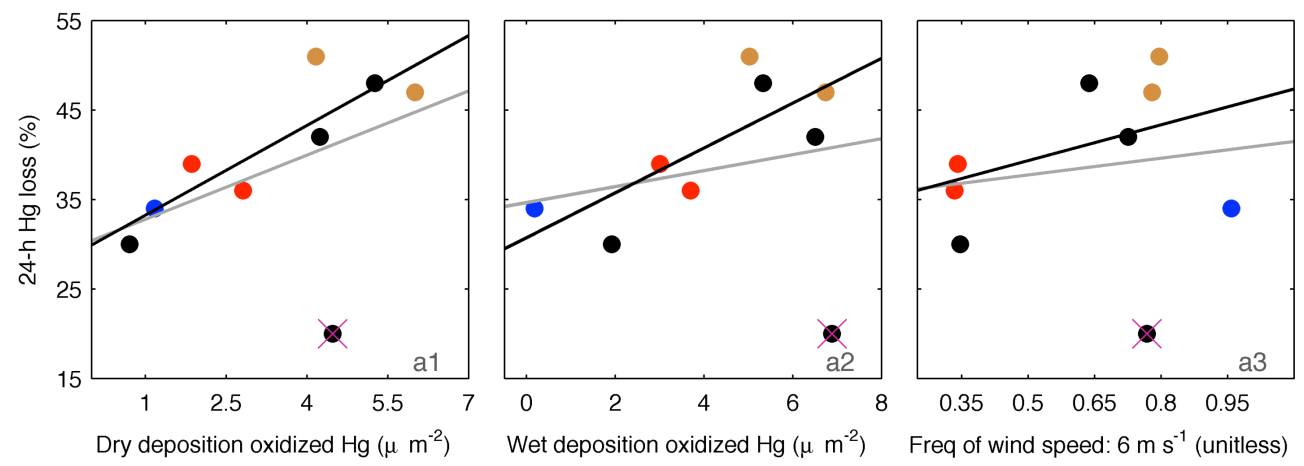

Fig. 3. Scatter plots of sufficiently strongly and significantly correlated model environmental variables with Set2's 24-h fractional loss of mercury from surface snow. The colour coding follows that of Fig. 2. The black line was estimated by the bivariate linear regression for Set2.
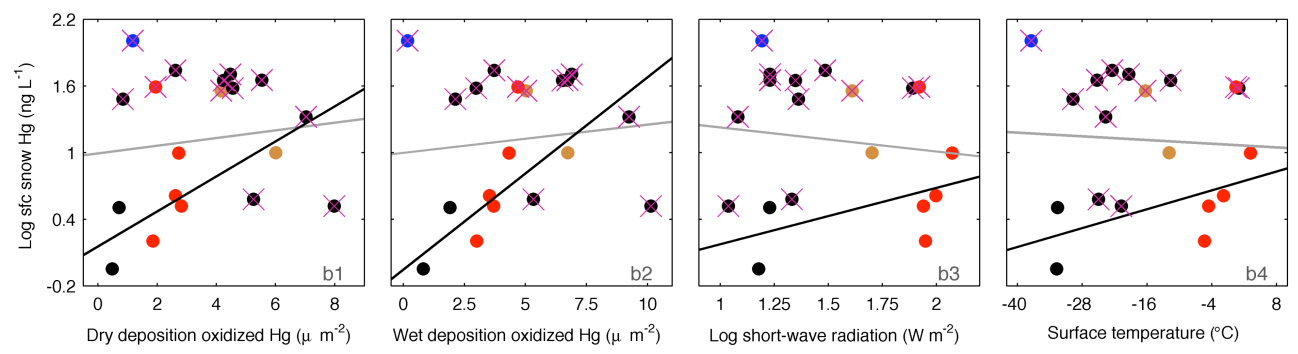

Fig. 4. Scatterplots of sufficiently strongly and significantly correlated model environmental variables with Set2's concentration of mercury in surface snow. Plotted as per Fig. 3. Additionally, a red "x" overlays mercury observations that are included in Set1 but not Set2.

the snowpack, leading to elevated concentrations once the meltwater exits the snowpack. Indeed, it is known that multiple melt-freeze cycles enhance concentrations in the ionic pulse (Kuhn, 2001). Interestingly, the signs of the correlations with albedo (Alb) and surface temperature (SfcT) have also reversed for the concentration of mercury in the meltwater's ionic pulse as compared to for seasonal snowpacks; the signs of these correlations now agree with theoretical arguments where increased solar insolation and atmospheric warming promote revolatilization (Sect. 2) and reduce the concentration of mercury in snowpacks and, consequently, in the snowpack meltwater's ionic pulse. Similarly, since turbulent kinetic energy (TKE) promotes snowpack ventilation (Sect. 2), which reduces the concentration of mercury in snowpacks, the negative correlation of turbulent kinetic energy with the concentration of mercury in the snowpack meltwater's ionic pulse is expected. However, it is uncertain why both wind speed-related variables (WdSpAv, $\mathrm{WdSpF} 6$ ) are positively correlated with the concentration of mercury in the meltwater's ionic pulse, given that wind-induced snowpack ventilation promotes mercury revolatilization (Kuhn, 2001; Albert and Shultz, 2002; Steffen et al., 2002; Lahoutifard et al., 2005; Anderson and Neff, 2008; Steen et al., 2009). Nonetheless, the scatter plots confirm that these two correlations are valid (Fig. 6).

The concentration of mercury in long-term snowpackrelated records is correlated with the fewest model environ- mental variables of the five types of mercury observations (Table 11). The positive correlation with short-wave insolation absorbed at the ground (SW) is not related to photoreduction; such a relationship would produce anticorrelation. Instead, the positive correlation and the scatter plot for this variable (Fig. 7) suggest a latitudinal gradient in these mercury concentrations. Indeed, the average mercury concentrations in high-latitude and mid-latitude long-term snowpackrelated records are 3.1 and $5.0 \mathrm{ng} \mathrm{L}^{-1}$, respectively (Table 5). It may be that none of the high-latitude glaciers are in locations affected by AMDEs and their important mercury deposition, while midlatitude glaciers are more affected by the predominantly midlatitude sources of anthropogenic mercury. Even natural sources of mercury, given the presence of the strong midlatitude upper-level zonal winds, may be more strongly represented in mid-latitude long-term snowpackrelated records. The anticorrelation between surface pressure $(\mathrm{SfcP})$ and this mercury concentration likely reflects the fact that the sunnier, drier conditions that accompany higher pressures promote photoreduction and, consequently, revolatilization, as well as reduce the likelihood of mercury being deposited through wet deposition or being buried by fresh snowfalls.

Considering all five types of mercury observations, Set2's collection of correlated model environmental variables is far more closely aligned with theoretical considerations than Set1's collection (Sect. 2). The success of Set2's results is 

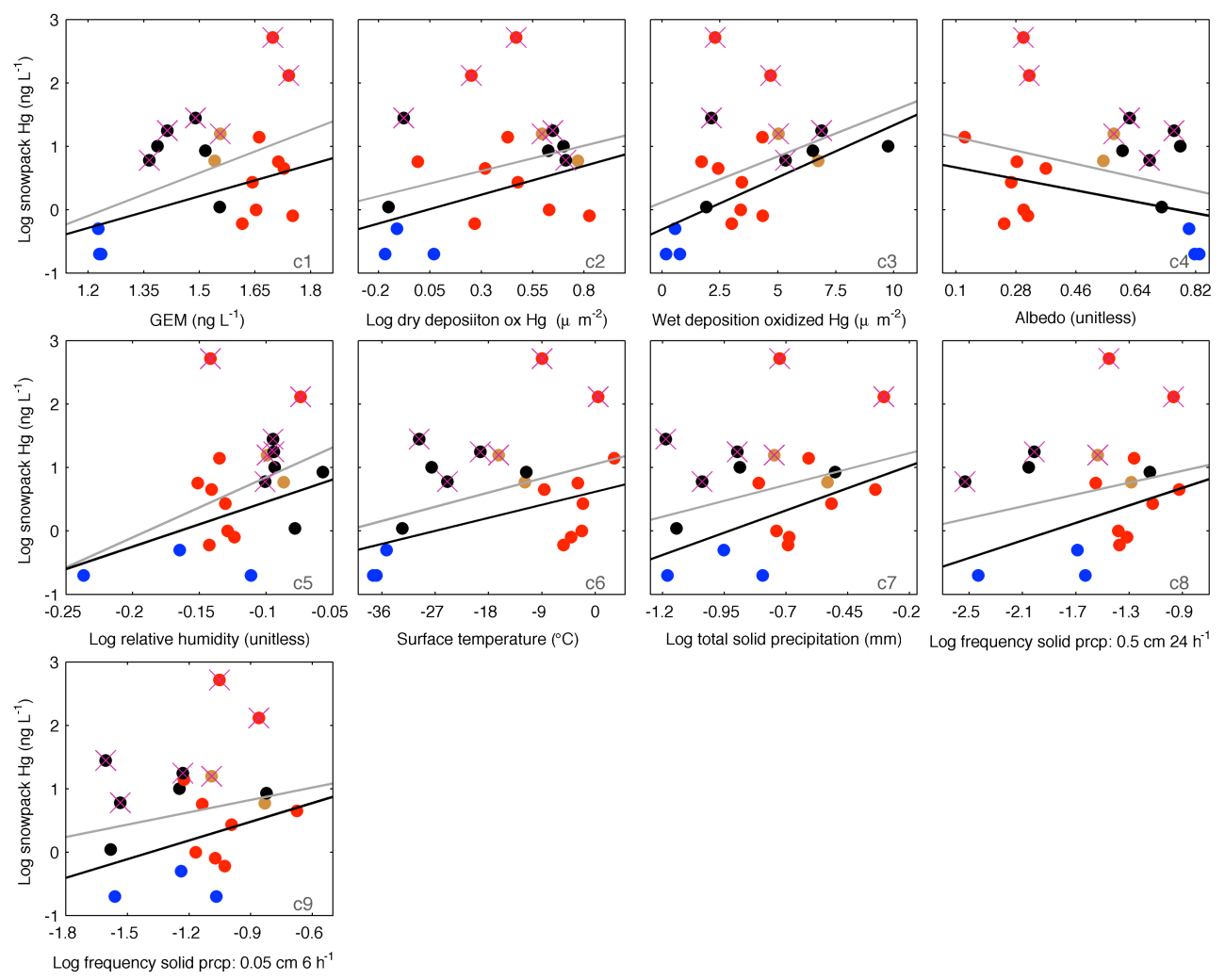

Fig. 5. Scatter plots of sufficiently strongly and significantly correlated model environmental variables with Set2's concentration of mercury in seasonal snowpacks. Plotted as per Fig. 4.

caused by our exclusion of observations that are known or deemed likely to be affected by halogens in the snowpackrelated medium (Sect. 3.3). Our results suggest strongly that the oxidation and stabilization of mercury in snowpacks by the snowpack's burden of halogens have a significant impact on the retention of mercury.

The suggested significant impact of halogen species on the fate of snowpack-related mercury indicates a potentially important consequence of climate change. Oxidizing halogen species are released to the atmosphere in association with refreezing sea ice leads (Grenfell and Maykut, 1977; Macdonald et al., 2005; Simpson et al., 2007a, 2007b; Zhao et al., 2008). Deposition of these species onto snowpacks follows (Snyder-Conn et al., 1997). Since some compounds formed within the snowpack between mercury and halides are stable (Lalonde et al., 2003; Ferrari et al., 2004b; Faïn et al., 2006, 2008; Bartels-Rausch et al., 2011), the revolatilization of the deposited mercury is reduced from snowpacks containing high concentrations of halides. Thus, if, in a warmer climate, sea ice becomes more dynamic, such that sea ice leads form and refreeze more frequently, deposition of halogens to snowpacks and, consequently, the retention of mercury by those snowpacks would increase; concentrations of mercury in snowpacks over sea ice may increase significantly. If so, the amount of mercury transferred to the underlying surface during snowmelt would also increase significantly.

Considering the overall importance of the individual correlated model environmental variables for Set2, we find that wet (WOxDp) and dry (DOxDp) depositions of oxidized mercury have the strongest impact on snowpack-related mercury variables. The fact that wet deposition is more strongly and more significantly correlated than dry deposition for concentrations of mercury in surface snow, seasonal snowpacks and the snowpack meltwater's ionic pulse, while the reverse is true for the 24-h fractional loss of mercury from surface snow, suggests that oxidized mercury deposited through wet processes is less available for revolatilization. The positive correlations between the three precipitation variables and the concentration of mercury in seasonal snowpacks reinforce this suggestion.

It is possible that the snowpack's greater retention of mercury deposited through wet processes is caused simply by the burial of the deposited mercury by fresh snow (Witherow and Lyons, 2008; Dommergue et al., 2010; Sect. 2). The new overlying snow would reduce the amount of solar radiation available and, consequently, diminish photoreduction within the snowpack and revolatilization. However, it is also possible that mercury deposited through dry processes tends to be located on the outer surface of the snowpack's snow grains, 

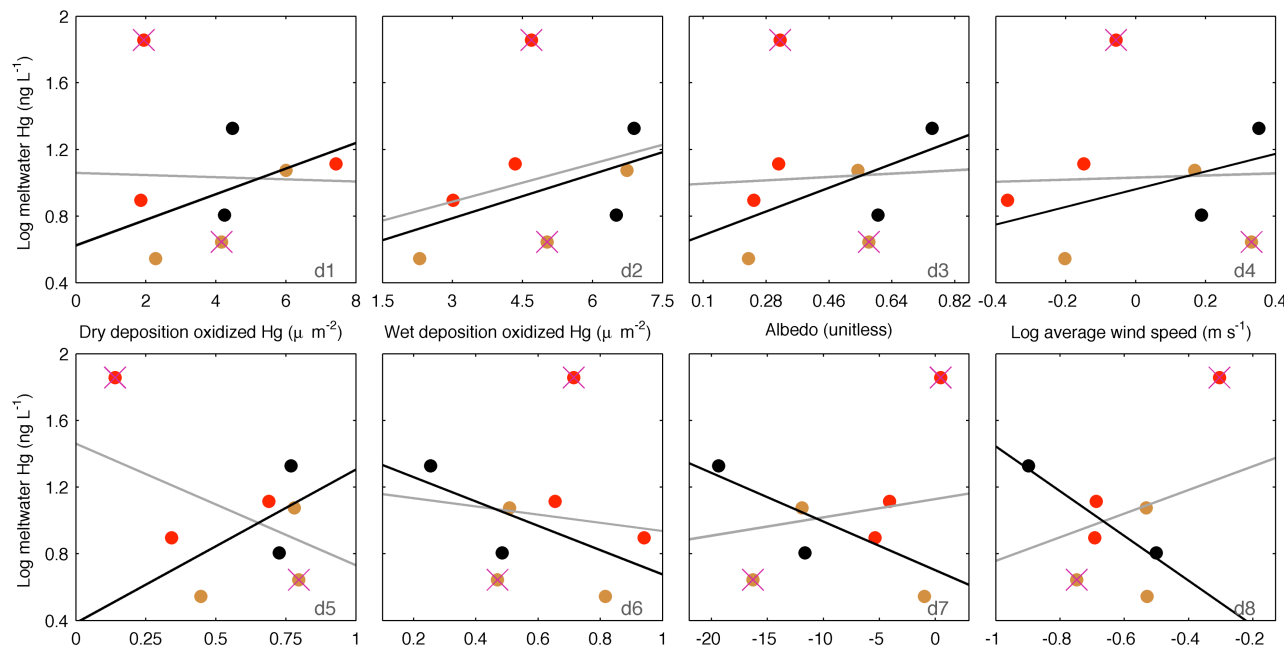

Wet deposition oxidized $\mathrm{Hg}\left(\mu \mathrm{m}^{-2}\right)$
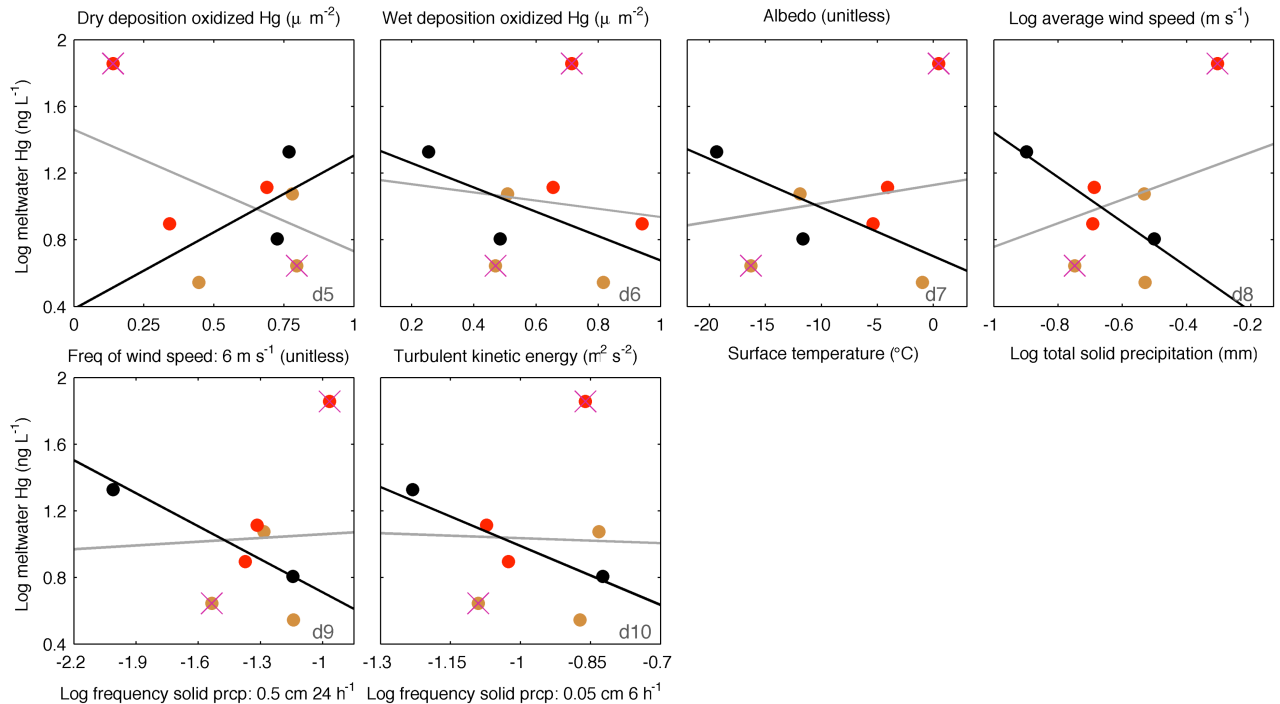

Log total solid precipitation $(\mathrm{mm})$

Fig. 6. Scatter plots of sufficiently strongly and significantly correlated model environmental variables with Set2's concentration of mercury in the snowpack meltwater's ionic pulse. Plotted as per Fig. 4.

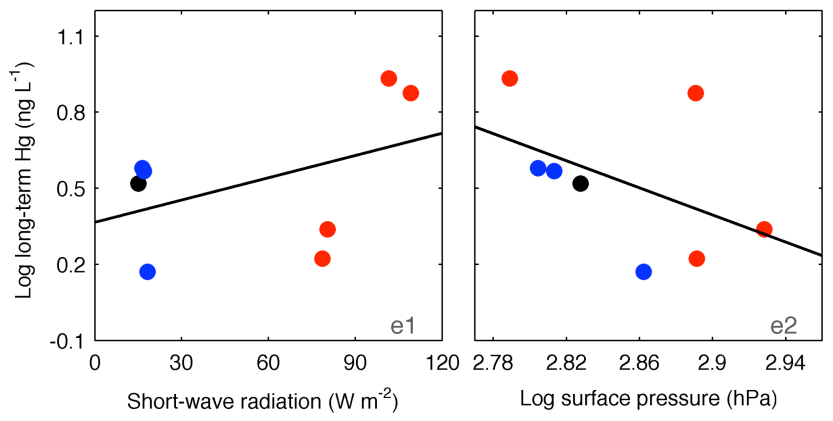

Fig. 7. Scatter plots of sufficiently strongly and significantly correlated model environmental variables with Set2's concentration of mercury in long-term snowpack-related records. Plotted as per Fig. 4.

having adsorbed onto the grains after being deposited, while mercury deposited through wet processes tends to be located in the interior of the snow grains. If so, mercury deposited through wet processes would be less easily photoreduced, and any GEM produced would be less easily revolatilized. Douglas et al. (2008) proposed a conceptual model to describe the mass balance of snow and ice crystals in terms of both water vapour and mercury. They remarked that little is known about either the absorption of RGM in water and ice, although the solubility of RGM undoubtedly increases with temperature, or about the adsorption of PHg onto ice crystals. However, it is known that the adsorption of RGM onto ice crystals depends on the crystal's surface area. The specific surface area of cloud ice particles is 2 to 4 orders of magnitude greater than that of larger, more fully developed snow crystals. These authors also posited that mercury adsorbed onto ice particles is locked into the ice lattice by the addition of further layers of ice through vapour deposition. The trapped mercury is likely retained until those ice layers are removed by sublimation or melting. Since snow grains undergo metamorphism within the snowpack (Kuhn, 2001; Mizukami and Perica, 2008; Durnford and Dastoor, 2011), the trapped mercury may be released gradually over time prior to the melting of the snowpack. Additionally, Seigneur et al. (1998) remarked that up to $50 \%$ of atmospheric mercury, primarily as RGM, may adsorb onto soot particles. These particles may then constitute ice or cloud condensation nuclei. Thus, whether RGM adsorbs onto an ice crystal's surface, which occurs preferentially in the early stages of crystal growth, or PHg forms the ice crystal's nucleus, theoretical considerations support this study's conclusion that mercury deposited onto snowpacks through wet deposition is less available for revolatilization than mercury deposited through dry deposition. 
The preferential retention of mercury deposited onto snowpacks through wet, rather than dry, deposition processes is an important result. If precipitation patterns change in a changing climate, the spatial distribution of wet deposition will change. Consequently, the spatial distribution of the concentration of mercury in snowpacks and their meltwater's ionic pulse will also likely change. As a result, the spatial distribution of the concentration of mercury in fish and marine mammals may also change.

\subsubsection{Multiple linear regressions}

The initial multiple linear regression performed for each mercury observation type included all that observation type's correlated model environmental variables (Table 12). Of these initial models, the $R^{2}$ values are highest for the concentrations of mercury in the snowpack meltwater's ionic pulse $\left(R^{2}=1.00\right)$, seasonal snowpacks $\left(R^{2}=0.97\right)$ and surface snow $\left(R^{2}=0.92\right)$. Unfortunately, these three initial models are over-fitted (Sect. 3.3); 10 environmental variables predict 6 meltwater mercury observations, 9 variables predict 14 snowpack concentrations and 4 variables predict 7 concentrations of mercury in surface snow (Tables 2-4, 11). The performances of the two initial models that are not over-fitted are encouraging: for 3 environmental variables predicting $8 \mathrm{ob}-$ servations of the 24-h fractional loss of mercury from surface snow, $R^{2}=0.78$ and $p$-value $=0.08$ (Tables 1,11 ); for 2 environmental variables predicting 8 observations of the concentration of mercury in long-term snowpack-related records, $R^{2}=0.70$ and $p$-value $=0.05$ (Tables 5,11$)$.

Given that three of the five initial models were over-fitted, experiments were conducted to determine which model environmental variables are the most useful for predicting a given type of mercury observation. The first experiment excluded the least readily obtainable environmental variables: dry deposition of oxidized mercury ( $\mathrm{DOxDp}$ ) and turbulent kinetic energy (TKE) are difficult to measure, and albedo (Alb) is not always available. The $R^{2}$ values of the new models generated for the fractional loss of mercury and the concentrations of mercury in surface snow and seasonal snowpacks are noticeably lower than those of the initial models $(0.78$ to $0.71,0.92$ to 0.77 , and 0.97 to 0.69 , respectively). The $R^{2}$ value of the new model generated for the concentration of mercury in the snowpack meltwater's ionic pulse remains unchanged at 1.00; the new model is also over-fitted. No new model was generated for mercury concentrations in longterm snowpack-related records; none of the environmental variables of interest are correlated with this concentration. Thus, the inclusion of the least readily accessible variables in the multiple linear regressions is necessary.

The second and third experiments test the importance of significance. For the 24-h fractional loss of mercury from surface snow, only the two depositions of oxidized mercury (DOxDp, WOxDp) are significantly correlated at either the $85 \%$ or $95 \%$ confidence level. The ability of the model gen- erated from the two deposition variables to explain the observations' variability remains virtually unchanged from that of the initial model $\left(R^{2}=0.78\right.$ to 0.77$)$. However, the model based on deposition alone is characterized by a greater degree of significance than the initial model ( $p$-value: 0.08 to 0.03 ). For the concentration of mercury in surface snow, the two deposition variables are, once again, the only variables that are correlated significantly at either the $85 \%$ or the $95 \%$ confidence level. The model generated from these two variables is characterized by a considerably lower $R^{2}$ value than the initial model ( 0.92 to 0.84$)$. However, the reliability of the model has increased; it is no longer over-fitted and the confidence level of the model's significance has increased from $85 \%$ to $97 \%$. For the concentration of mercury in seasonal snowpacks, the model generated from environmental variables that are significantly correlated at the $85 \%$ confidence level is characterized by an $R^{2}$ value of 0.84 . Increasing the minimum confidence level to $95 \%$ decreases the generated model's $R^{2}$ value to 0.64 . Since the number of participating environmental variables has decreased from 7 in the former model to 3 in the latter, the former model is over-fitted for the 14 mercury observations while the latter is not; the former model, like the initial model, is unreliable. Thus, neither of these two models is desirable. For the concentration of mercury in the snowpack meltwater's ionic pulse, no model environmental variables are significantly correlated at the $95 \%$ confidence level. Given that the 4 environmental variables significantly correlated at the $85 \%$ confidence level generate an over-fitted model for the 6 observations, the $R^{2}$ value of 0.77 is low. No model environmental variables are correlated significantly at either the $85 \%$ or $95 \%$ confidence level with the concentration of mercury in long-term records.

For the fourth experiment, we tested how accurately the two depositions of oxidized mercury (DOxDp, WOxDp) alone could predict each type of mercury observation. None of the five models generated in this experiment is over-fitted. The most successful model was produced for the concentration of mercury in surface snow $\left(R^{2}=0.84\right.$, $p$-value $=0.03$ ), followed by the $24-\mathrm{h}$ fractional loss of mercury from surface snow $\left(R^{2}=0.77, p\right.$-value $\left.=0.03\right)$, and the concentrations of mercury in seasonal snowpacks $\left(R^{2}=0.51, p\right.$-value $\left.=0.02\right)$, the snowpack meltwater's ionic pulse $\left(R^{2}=0.52, p\right.$-value $\left.=0.33\right)$ and long-term snowpackrelated records $\left(R^{2}=0.20, p\right.$-value $\left.=0.58\right)$. The varying performances of these models suggest that environmental processes other than the deposition of oxidized mercury exert the least control over the concentration of mercury in surface snow. However, the dominance of the two deposition variables in predicting snowpack-related mercury values diminishes as mercury is revolatilized and as the snowpack deepens and melts. This is to be expected given that these processes either indicate the passage of time and/or imply meteorological activity. In either case, environmental processes other than mercury deposition have a greater opportunity to influence the mercury values. 
Considering the four experiments performed, model 5 , which includes only the deposition of oxidized mercury through dry and wet processes, is considered the most successful model for the 24-h fractional loss of mercury from surface snow; this model is characterized by the smallest $p$ value (0.03) while its $R^{2}$ value (0.77) is only barely under the highest $R^{2}$ value (0.78) achieved for this type of mercury observation. For the concentration of mercury in longterm snowpack-related records, the initial model, model 38, is considered the best model; its $R^{2}$ value ( 0.70$)$ is by far the highest for this type of mercury observation and its $p$-value (0.05) by far the lowest. Model 38 includes shortwave radiation and surface pressure. The best model for each mercury observation type is indicated in bold face in Table 12. Table 13 provides the intercept and variable coefficients of the best models.

For the concentration of mercury in surface snow, further experiments were performed to determine the best model. Adding either shortwave radiation (SW) or surface temperature ( $\mathrm{SfcT}$ ) to the model involving only the two depositions improved the model's $R^{2}$ value modestly $(0.84$ to $\sim 0.86)$ but degraded the $p$-value ( 0.03 to 0.08$)$. Hence, the model involving the two depositions alone (model 10) is deemed the best for this mercury observation type.

Models for the concentration of mercury in seasonal snowpacks are prone to over-fitting, given that 9 model environmental variables are correlated with the 14 available observations; potential models should include 6 environmental variables at most. Models based on various combinations of the correlated environmental variables were tested (Table 12). Since involving fewer environmental variables is considered preferable, both to avoid over-fitting and for the sake of simplicity, model 19 (4 variables; $R^{2}=0.79$ ) is considered better than models $20-22$ (5 variables, $R^{2}=0.79$ to 0.82 ) despite their occasionally higher $R^{2}$ values; the $p$-values of models 19 to 22 are comparable $(\leq 0.01)$. Model 19 includes the two depositions of oxidized mercury (DOxDp, WOxDp), surface temperature (SfcT) and total solid precipitation (PrTot). Models 23 and 24 test the impact of the different precipitation variables. Since total precipitation is more readily available than the frequency of precipitation above a specified threshold, and since the $R^{2}$ value of model $19(0.79)$ is marginally higher than those $(0.78)$ of models 23 and 24 while the three $p$-values are comparable $(\leq 0.01)$, total solid precipitation (PrTot; model 19) is deemed to produce a better model than either the frequency of at least $5 \mathrm{~mm}$ of solid precipitation over $24 \mathrm{~h}$ (PrF24h; model 23) or of at least $0.5 \mathrm{~mm}$ over $6 \mathrm{~h}$ (PrF6h; model 24). Model 25, which excludes surface temperature $(\mathrm{SfcT})$, indicates that the inclusion of this variable in model 19 is highly beneficial; the $R^{2}$ value decreases from 0.79 for model 19 to 0.66 for model 25 while the $p$-values are comparable $(\leq 0.01)$. Thus, the model that is considered the best for predicting the observed concentrations of mercury in seasonal snowpacks is model 19.
Models for the concentration of mercury in the snowpack meltwater's ionic pulse are also prone to over-fitting, given that 10 model environmental variables are correlated with the 6 available observations; potential models should include 2 environmental variables at most. To avoid excessive experimentation with combinations of environmental variables, we assume that the wet deposition of oxidized mercury is one of the two permitted variables. It seems reasonable to assume that an environmental variable related to mercury should be included in any model. The concentration of atmospheric GEM is uncorrelated with the concentration of mercury in the snowpack meltwater's ionic pulse (Table 11). The wet deposition of oxidized mercury is more strongly $(R=0.66)$ and significantly ( $p$-value $=0.16)$ correlated with this mercury concentration than dry deposition of oxidized mercury $(R=0.60, p$-value $=0.21)$. Models including every other model environmental variable that is characterized by an absolute value of the correlation coefficient of at least 0.60 (i.e., $|R| \geq 0.60$ ) with this mercury concentration and a $p$ value of no more than 0.20 were successively tested. Models 31 to 37 underline the overwhelming importance of precipitation in determining the concentration of mercury in the snowpack meltwater's ionic pulse; the $R^{2}$ values of the models involving any of the three precipitation variables (PrTot, PrF24h, PrF6h; models 35 to 37 ) range from 0.75 to 0.86 while the $p$-values range from 0.05 to 0.13 . The remaining models in this set (models 31 to 34 ) are characterized by $R^{2}$ values ranging from 0.43 to 0.52 and $p$-values ranging from 0.34 to 0.43 . The model that is considered the best for predicting the observed concentration of mercury in the snowpack meltwater's ionic pulse is model 35. The $R^{2}$ value of this model (0.84) is close to the highest $R^{2}$ value of any model that is not over-fitted (0.86), the relationship is significant at the $94 \%$ confidence level, and the precipitation variable (PrTot) is readily available.

\section{Summary and conclusions}

In this statistical study we used the mean values of 5 types of snowpack-related mercury observations and the five-year average of 20 model environmental variables as simulated by GRAHM. The snowpack-related mercury observations were gathered from published reports of field studies. The model environmental variables represent the controls on the physical and chemical processes that govern the behavior of snowpack-related mercury.

We performed two sets of calculations for this study. We first calculated bivariate correlation coefficients, and the confidence level of their significance, between each type of snowpack-related mercury observation and each of the model environmental variables. Sufficiently strongly and significantly correlated environmental variables, where the absolute value of the correlation coefficient was at least 0.35 (i.e., $(|R| \geq 0.35)$ and the confidence level of the significance at 
least $70 \% p$-value $\leq 0.30$ ), subsequently participated in multiple linear regressions for the given observation type.

The first set of calculations, Set1, involved all available snowpack-related mercury observations. Observations that are known or are considered likely to have been strongly affected by the oxidation and/or stabilization of mercury within the snowpack by the snowpack's halogen content were excluded from the second set of calculations, Set2. Since no observations of mercury in long-term snowpack-related records were known or deemed likely to have been affected by halogens, this group of mercury observations was assigned to Set2 alone.

For each of the four types of snowpack-related mercury observations participating in both Set1 and Set2, the average correlation of the sufficiently strongly and significantly correlated model environmental variables increased for Set2 over Set1. The number of correlated model environmental variables also increased for Set 2 over Set 1 for all four mercury observation types. Furthermore, the collection of model environmental variables that are sufficiently strongly and significantly correlated with Set 2 is far more closely aligned with theoretical considerations than Set1's collection. Finally, the ability of multiple linear regression models to predict snowpack-related mercury values improved considerably for Set2 (average $R^{2}=0.79$, average $p$-value $=0.03$ ) over Set1 (average $R^{2}=0.37$, average $p$-value $=0.19$ ). Since the only difference between Set1 and Set2 is the presence of halogens in the snowpack, these results suggest strongly that the oxidation and stabilization of mercury in snowpacks by the snowpack's burden of halogens have a significant impact on the behavior of the mercury. This result has important implications for climate change. In a warmer climate, leads would likely appear more frequently in the sea ice pack. Consequently, the deposition of halogens onto snowpacks would increase. As a result of the greater retention of deposited mercury by the affected snowpacks, the eventual transfer of mercury to the underlying surface with the snowpack's meltwater would be enhanced.

The best multiple linear regression model from Set2 for each of the five mercury observation types is able to explain from $70 \%$ to $84 \%$ of the observations' variability. These models are significant at the $94 \%$ to $>99 \%$ confidence level. The models for the concentrations of mercury in surface snow and the snowpack meltwater's ionic pulse are the most successful at explaining the observations' variability. The model for the concentration of mercury in long-term snowpack-related records is the least successful.

The best models for four of the five mercury observation types include the wet deposition of oxidized mercury. Three of the best models also include the dry deposition of oxidized mercury. Consequently, the two deposition variables are the model environmental variables that are included the most frequently in the best regression models. Two of the five best models involve total precipitation. The importance of precipitation reinforces the impact of the wet deposition of oxidized mercury on snowpack-related mercury values. Other variables appearing in a single best model include surface temperature, short-wave radiation and surface pressure. These results are realistic. Interestingly, the best regression model for the concentration of mercury in long-term snowpack-related records involves neither a mercury deposition variable nor a precipitation variable. This mercury observation type appears to be determined to a certain extent by latitude. This may reflect the importance either of midlatitude anthropogenic sources of mercury or of strong midlatitude upper-level zonal winds.

This study's results suggest that snowpacks retain oxidized mercury deposited through wet processes preferentially over oxidized mercury deposited through dry processes. This preferential retention may reflect the importance of the burial of deposited mercury by fresh snowfalls (Witherow and Lyons, 2008; Dommergue et al., 2010) and/or the more central location within a snowpack's snow grain of mercury deposited through wet versus dry processes (Seigneur et al., 1998; Douglas et al., 2008). The preferential retention by snowpacks of mercury deposited through wet processes has important implications for climate change. If precipitation patterns change in a changing climate, the spatial distribution of wet deposition will also change. As a result, the spatial distributions of snowpack mercury concentrations and of the transfer of mercury to the underlying surface with the snowpack's meltwater will also change.

The success of each mercury observation type's best model indicates that snowpack-related mercury observations do, indeed, have the potential to further constrain and help improve atmospheric mercury models. However, observations at a wider variety of locations are required to validate the developed regression models. Moreover, as snowpackrelated mercury observations become available at new locations, the regression models can be refined; more environmental variables will be able to be included before the models become over-fitted. In the future, including concentrations of the snowpack's content of halogens and other oxidants and stabilizing agents in the multiple linear regressions would permit an explicit evaluation of the importance of these chemical processes to snowpack-related mercury observations.

Acknowledgements. The authors are thankful for funds provided for this study by the Government of Canada Program for International Polar Year (IPY) project of Intercontinental Atmospheric Transport of Anthropogenic Pollutants to the Arctic (INCATPA), and the Government of Canada's Clean Air Regulatory Agenda (CARA). Funding for the study performed by Steen et al. (2009) was received from the Norwegian Research Council, NFR (Miljø 2015, project number 181924/S30), Anders Jahres Fond til vitenskapens fremme, Direktør Halvor B. Holtas legat, Svalbard Science Forum and Elkem AS. We would like to thank the staff at the Norwegian Polar Institute and Kins Bay in Ny-Ålesund for logistic support. Alfred Wegener Institute, Koldeway station in Ny-Ålesund 
is acknowledged for meteorological data. Feiyue Wang's comments were greatly appreciated. Suggestions from anonymous reviewers contributed significantly to this manuscript.

Edited by: R. Cohen

\section{References}

Albert, M. R. and Shultz, E. F.: Snow and firn properties and airsnow transport processes at Summit, Greenland, Atmos. Environ., 36, 2789-2797, 2002.

Allan, C. J., Heyes, A., Roulet, N. T., St. Louis, V. L., and Rudd, J. W. M.: Spatial and temporal dynamics of mercury in Precambrian Shield upland runoff, Biogeochemistry, 52, 13-40, 2001.

Anderson, P. S. and Neff, W. D.: Boundary layer physics over snow and ice, Atmos. Chem. Phys., 8, 3563-3582, doi:10.5194/acp-83563-2008, 2008.

Andersson, M. E., Gårdfeldt, K., Wängberg, I., and Strömberg, D.: Determination of Henry's law constant for elemental mercury, Chemosphere, 73, 587-592, doi:10.1016/j.chemosphere.2008.05.067, 2008a.

Ariya, P. A., Dastoor, A. P., Amyot, M., Schroeder, W. H., Barrie, L., Anlauf, K., Raofie, F., Ryzhkov, A., Davignon, D., Lalonde, J., and Steffen, A.: The Arctic: a sink for mercury, Tellus, Ser. B, 56, 397-403, 2004.

Aspmo, K., Temme, C., Berg, T., Ferrari, C., Gauchard, P.-A., Fain, X., and Wibetoe, G.: Mercury in the atmosphere, snow and melt water ponds in the North Atlantic Ocean during Arctic summer, Environ. Sci. Technol., 40, 4083-4089, 2006.

Babyak, M. A.: what you see may not be what you get: A brief, nontechnical introduction to over-fitting in regression-type models, Psychosom. Med., 66, 411-421, 2004.

Bales, R. C., Davis, R. E., Stanley, D. A.: Ion elution through shallow homogeneous snow, Water Resour. Res., 25, 1869-1877, 1989.

Bales, R. C., Sommerfeld, R. A., and Kebler, D. G.: Ionic tracer movement through a Wyoming snowpack, Atmos. Environ., 24, 2749-2758, 1990.

Balogh, S. J., Meyer, M. L., Hansen, N. C., Moncrief, J. F., Gupta, S. C.: Transport of mercury from a cultivated field during snowmelt, J. Environ. Qual., 29, 871-874, 2000.

Bartels-Rausch, T., Huthwelker, T., Jöri, M., Gäggeler, H. W., Ammann, M.: Interaction of gaseous elemental mercury with snow surfaces: laboratory investigation, Environ. Res. Lett., 3, 045009 , doi:10.1088/1748-9326/3/4/045009 2008.

Bartels-Rausch, T., Krysztofiak, G., Bernhard, A., Schläppi, M., Schwikowski, M., and Ammann, M.: Photoinduced reduction of divalent mercury in ice by organic matter, Chemosphere, 82 , 199-203, 2011.

Beine, H. J., Amoroso, A., Dominé, F., King, M. D., Nardino, M., Ianniello, A., and France, J. L.: Surprisingly small HONO emissions from snow surfaces at Browning Pass, Antarctica, Atmos. Chem. Phys., 6, 2569-2580, doi:10.5194/acp-6-2569-2006, 2006.

Belsley, D. A., Kuh, E., and Welsch, R. E.: Regression Diagnostics: Identifying Influential Data and Sources of Collinearity, John Wiley \& Sons, Inc., Hoboken, NJ, USA, 292 pp., 1980.

Berg, T., Bartnicki, J., Munthe, J., Lattila, H., Hrehoruk, J., and Mazur, A.: Atmospheric mercury species in the European Arctic: measurements and modeling, Atmos. Environ., 35, 2569-2582, 2001.

Berg, T., Sekkesæter, S., Steinnes, E., Valdal, A.-K., and Wibetoe, G.: Springtime depletion of mercury in the European Arctic as observed at Svalbard, Sci. Total Environ., 304, 43-51, 2003.

Bishop, K., Lee, Y.-H., Pettersson, C., and Allard, B.: Methylmercury output from the Svartberget catchment in Northern Sweden during spring flood, Water Air Soil Poll., 80, 445-454, 1995.

Bloom, N. S. and Watras, C. J.: Observations of methylmercury in precipitation, Sci. Total Environ., 87/88, 199-207, 1989.

Bottenheim, J. W., Fuentes, J. D., Tarasick, D. W., and Anlauf, K. G.: Ozone in the Arctic lower troposphere during winter and spring 2000 (ALERT2000), Atmos. Environ., 36, 2535-2544, 2002.

Brooks, S. B., Saiz-Lopez, A., Skov, H., Lindberg, S. E., Plane, J. M. C., and Goodsite, M. E.: The mass balance of mercury in the springtime arctic environment, Geophys. Res. Lett., 33, L13812, doi:10.1029/2005GL025525, 2006.

Brooks, S., Arimoto, R., Lindberg, S., and Southworth, G.: Antarctic polar plateau snow surface conversion of deposited oxidized mercury to gaseous elemental mercury with fractional long-term burial, Atmos. Environ., 42, 2877-2884, 2008a.

Brooks, S., Lindberg, S., Southworth, G., and Arimoto, R.: Springtime atmospheric mercury speciation in the McMurdo, Antarctica coastal region, Atmos. Environ., 42, 2885-2893, 2008 b.

Boutron, C. F., Vandal, G. M., Fitzgerald, W. F., and Ferrari, C. P.: A forty year record of mercury in central Greenland snow, Geophys. Res. Lett., 25, 3315-3318, 1998.

Capelli, R., Minganti, V., Chiarini, C., and De Pellegrini, R.: Mercury in snow layers from the Antarctica, Int. J. Environ. An. Ch., 71, 289-296, 1998.

Chatterjee, S. and Hadi, A. S.: Influential Observations, High Leverage Points, and Outliers in Linear Regression, Stat. Sci., 1, 379416, 1986.

Christensen, J. H., Brandt, J., Frohn, L. M., Skov, H.: Modelling of mercury in the Arctic with the Danish Eulerian Hemispheric Model, Atmos. Chem. Phys., 4, 2251-2257, doi:10.5194/acp-42251-2004, 2004.

Cobbett, F. D., Steffen, A., Lawson, G., and Van Heyst, B. J.: GEM fluxes and atmospheric mercury concentrations (GEM, RGM and $\mathrm{Hg}^{p}$ ) in the Canadian Arctic at Alert, Nunavut, Canada (February-June 2005), Atmos. Environ., 41, 6527-6543, 2007.

Cole, A. S. and Steffen, A.: Trends in long-term gaseous mercury observations in the Arctic and effects of temperature and other atmospheric conditions. Atmos. Chem. Phys., 10, 4661-4672, doi:10.5194/acp-10-4661-2010, 2010.

Constant, P., Poissant, L., Villemur, R., Yumvihoze, E., and Lean, D.: Fate of inorganic mercury and methyl mercury within the snow cover in the low arctic tundra on the shore of Hudson Bay (Québec, Canada), J. Geophys. Res., 112, D08309, doi:10.1029/2006JD007961, 2007.

Cook, R. D. and Weisberg S.: Residuals and Influence in Regression, Chapman \& Hall/CRC Press, New York, USA, 230 pp., ISBN 0-412-24280-0, 1982.

Côté, J., Desmarais, J.-G., Gravel, S., Méthot, A., Patoine, A., Roch, M., and Staniforth, A.: The operational CMC-MRB Global Environmental Multiscale (GEM) Model: Part II - Results, Mon. Weather Rev., 126, 1397-1418, 1998a. 
Côté, J., Gravel, S., Méthot, A., Patoine, A., Roch, M., and Staniforth, A.: The operational CMC-MRB Global Environmental Multiscale (GEM) Model: Part I - Design considerations and formulation, Mon. Weather Rev., 126, 1373-1395, 1998b.

Cressman, G. P.: An operational objective analysis system, Mon. Weather Rev., 87, 367-374, 1959.

Dastoor, A. P. and Larocque, Y.: Global circulation of atmospheric mercury: A modeling study, Atmos. Environ., 38, 147-161, 2004.

Dastoor, A. P., Davignon, D., Theys, N., Van Roozendael, M., Steffen, A., and Ariya, P. A.: Modeling dynamic exchange of gaseous elemental mercury at polar sunrise, Environ. Sci. Technol., 42, 5183-5188, doi:10.1021/es800291w, 2008.

Domine, F., Sparapani, R., Ianniello, A., and Beine, H. J.: The origin of sea salt in snow on Arctic sea ice and in coastal regions, Atmos. Chem. Phys., 4, 2259-2271, doi:10.5194/acp-4-2259-2004, 2004.

Domine, F., Albert, M., Huthwelker, T., Jacobi, H.-W., Kokhanovsky, A. A., Lehning, M., Picard, G., Simpson, W. R.: Snow physics as relevant to snow photochemistry, Atmos. Chem. Phys., 8, 171-208, doi:10.5194/acp-8-171-2008, 2008.

Dommergue, A., Ferrari, C. P., Gauchard, P.-A., and Boutron, C. F.: The fate of mercury species in a sub-arctic snowpack during snowmelt, Geophys. Res. Lett., 30, 1621, doi:10.1029/2003GL017308, 2003.

Dommergue, A., Bahlmann, E., Ebinghaus, R., Ferrari, C., and Boutron, C.: Laboratory simulation of $\mathrm{Hg}^{0}$ emissions from a snowpack, Anal. Bioanal. Chem., 388, 319-327, 2007.

Dommergue, A., Larose, C., Faïn, X., Clarisse, O., Foucher, D., Hintelmann, H., Schneider, D., and Ferrari, C. P.: Deposition of mercury species in the $\mathrm{Ny}$-Ålesund area $\left(79^{\circ} \mathrm{N}\right)$ and their transfer during snowmelt, Environ. Sci. Technol., 44, 901-907, doi:10.1021/es902579m, 2010.

Douglas, T. A., Sturm, M., Simpson, W. R., Blum, J. D., AlvarezAviles, L., Keeler, G. J., Perovich, D. K., Biswas, A., and Johnson, K.: Influence of snow and ice crystal formation and accumulation on mercury deposition to the Arctic, Environ. Sci. Technol., 42, 1542-1551, 2008.

Durnford, D. and Dastoor, A.: The behavior of mercury in the cryosphere: A review of what we know from observations, J. Geophys. Res., 116, D06305, doi:10.1029/2010JD014809, 2011.

Durnford, D., Dastoor, A., Figueras-Nieto, D., and Ryjkov, A.: Long range transport of mercury to the Arctic and across Canada, Atmos. Chem. Phys., 10, 6063-6086, doi:10.5194/acp-10-60632010, 2010.

Durnford, D., Dastoor, A., Ryzhkov, A., Poissant, L., Pilote, M., and Figueras-Nieto, D.: How relevant is the deposition of mercury onto snowpacks? - Part 2: A modeling study, Atmos. Chem. Phys., 12, 9251-9274, doi:10.5194/acp-12-9251-2012, 2012.

Ebinghaus, R., Jennings, S. G., Kock, H. H., Derwent , R. G., Manning, A. J., and Spain, T. G.: Decreasing trends in total gaseous mercury observations in baseline air at Mace Head, Ireland from 1996 to 2009. Atmos. Environ., 45, 3475-3480, doi:10.1016/j.atmosenv.2011.01.033, 2011.

Environment Canada: Numerical Weather Prediction (NWP) Model Verification, available at http://www.weatheroffice.gc.ca/ verification/index_e.html, 2012.

Eyrikh, S., Schwikowski, M., Gäggeler, H. W., Tobler, L., and Papina, T.: First mercury determination in snow and firn from high- mountain glaciers in the Siberian Altai by CV-ICP-MS, J. Phys. IV, 107, 431-434, 2003.

Fain, X., Ferrari, C. P., Gauchard, P.-A., Magand, O., and Boutron, C.: Fast depletion of gaseous elemental mercury in the Kongsvegen Glacier snowpack in Svalbard, Geophys. Res. Lett., 33, L06826, doi:10.1029/2005GL025223, 2006.

Faïn, X., Grangeon, S., Bahlmann, E., Fritsche, J., Obrist, D., Dommergue, A., Ferrari, C. P., Cairns, W., Ebinghaus, R., Barbante, C., Cescon, P., and Boutron, C.: Diurnal production of gaseous mercury in the alpine snowpack before snowmelt, J. Geophys. Res., 112, D21311, doi:10.1029/2007JD008520, 2007.

Faïn, X., Ferrari, C. P., Dommergue, A., Albert, M., Battle, M., Arnaud, L., Barnola, J.-M., Cairns, W., Barbante, C., and Boutron, C.: Mercury in the snow and firn at Summit Station, Central Greenland, and implications for the study of past atmospheric mercury levels, Atmos. Chem. Phys., 8, 3441-3457, doi:10.5194/acp-8-3441-2008, 2008.

Faïn, X., Ferrari, C. P., Dommergue, A., Albert, M. R., Battle, M., Severinghaus, J., Arnaud, L., Barnola, J.-M., Cairns, W., Barbante, C., and Boutron, C.: Polar firn air reveals large-scale impact of anthropogenic mercury emissions during the 1970s, P. Natl. Acad. Sci. USA, 106, 16114-16119, doi:10.1073/pnas.0905117106, 2009.

Fatnassi, H., Boulard, T., Poncet, C., and Chave, M.: Optimisation of greenhouse insect screening with computational fluid dynamics, Biosyst. Eng., 93, 301-312, 2006.

Ferrari, C. P., Dommergue, A., Veysseyre, A., Planchon, F., and Boutron, C. F.: Mercury speciation in the French seasonal snow cover, Sci. Total Environ., 287, 61-69, 2002.

Ferrari, C. P., Dommergue, A., Boutron, C. F., Skov, H., Goodsite, M., and Jensen, B.: Nighttime production of elemental gaseous mercury in interstitial air of snow at Station Nord, Greenland, Atmos. Environ., 38, 2727-2735, 2004.

Ferrari, C. P., Gauchard, P.-A., Aspmo, K., Dommergue, A., Magand, O., Bahlmann, E., Nagorski, S., Temme, C., Ebinghaus, R., Steffen, A., Banic, C., Berg, T., Planchon, F., Barbante, C., Cescon, P., and Boutron, C. F.: Snow-to-air exchanges of mercury in an Arctic seasonal snow pack in Ny-Ålesund, Svalbard, Atmos. Environ., 39, 7633-7645, 2005.

Ferrari, C. P., Padova, C., Faïn, X., Gauchard, P.-A., Dommergue, A., Aspmo, K., Berg, T., Cairns, W., Barbante, C., Cescon, P., Kaleshke, L., Richter, A., Wittrock, F., and Boutron, C.: Atmospheric mercury depletion event study in Ny-Alesund (Svalbard) in spring 2005. Deposition and transformation of $\mathrm{Hg}$ in surface snow during springtime, Sci. Total Environ., 397, 167-177, 2008.

Fitzgerald, W. F., Mason, R. P., and Vandal, G. M.: Atmospheric cycling and air-water exchange of mercury over mid-continental lacustrine regions, Water Air Soil Poll., 56, 745-767, 1991.

Fouquart, Y. and Bonnel, B.: Computations of solar heating of the earth's atmosphere: a new parameterization, Contrib. Atmos. Phys., 53, 35-62, 1980.

Garand, L. and Mailhot, J.: The influence of infrared radiation on numerical weather forecasts, in Proceedings of the 7th Conference on Atmospheric Radiation, J146-J151, American Meteorological Society, USA, 1990.

Garbarino, J. R., Snyder-Conn, E., Leiker, T. J., and Hoffman, G. L.: Contaminants in Arctic snow collected over Northwest Alaskan sea ice, Water Air Soil Poll., 139, 183-214, 2002. 
Gbor, P. K., Wen, D., Meng, F., Yang, F., and Sloan, J. J.: Sloan Modeling of mercury emission, transport and deposition in North America, Atmos. Environ., 41, 1135-1149, 2007.

Gilmour, C. C. and Henry, E. A.: Mercury methylation in aquatic systems affected by acid deposition, Environ. Pollut., 71, 131169, 1991.

Goulet, R. R., Holmes, J., Page, B., Poissant, L., Siciliano, S. D., Lean, D. R. S., Wang, F., Amyot, M., and Tessier, A.: Mercury transformations and fluxes in sediments of a riverine wetland, Geochim. Cosmochim. Ac., 71, 3393-3406, 2007.

Grenfell, T. C. and Maykut, G. A.: The optical properties of ice and snow in the Arctic Basin, J. Glaciol., 18, 445-463, 1977.

Hansen, K. M., Halsall, C. J., and Christensen, J. H.: A dynamic model to study the exchange of gas-phase persistent organic pollutants between air and a seasonal snowpack, Environ. Sci. Technol., 40, 2644-2652, doi:10.1021/es051685b, 2006.

Heidam, N. Z., Christensen, J., Wåhlin, P., and Skov, H.: Arctic atmospheric contaminants in NE Greenland: levels, variations, origins, transport, transformations and trends 1990-2001, Sci. Total Environ., 331, 5-28, 2004.

Hedgecock, I. M., Pirrone, N., and Sprovieri, F.: Chasing quicksilver northward: mercury chemistry in the Arctic troposphere, Environ. Chem., 5, 131-134, 2008.

Hicks, J., Marko, K., and Sahulka, D.: Metals in snow columns, in Flin Flon soils study, Tech. Rep. Appendix R, Hudson Bay Mining and Smelting Co., Ltd., Flin Flon, Manitoba, Canada, available at http://www.flinflonsoilsstudy.com/doclibrary.php, 2008.

Hirdman, D., Aspmo, K., Burkhart, J. F., Eckhardt, S., Sodemann, H., Stohl, A.: Transport of mercury in the Arctic atmosphere: evidence for a spring-time net sink and summer-time source, Geophys. Res. Lett., 36, L12814, doi:10.1029/2009GL038345, 2009.

Holmes, C. D., Jacob, D. J., Corbitt, E. S., Mao, J., Yang, X., Talbot, R., and Slemr, F.: Global atmospheric model for mercury including oxidation by bromine atoms, Atmos. Chem. Phys., 10, 12037-12057, doi:10.5194/acp-10-12037-2010, 2010.

Jackson, T. A.: Long-range atmospheric transport of mercury to ecosystems, and the importance of anthropogenic emissions - a critical review and evaluation of the published evidence, Environ. Rev., 5, 99-120, 1997.

Jitaru, P., Infante, H. G., Ferrari, C. P., Dommergue, A., Boutron, C. F., and Adams, F. C.: Present century record of mercury species pollution in high altitude alpine snow and ice, J. Phys IV, 107, 683-686, doi:10.1051/jp4:20030395, 2003.

Jitaru, P., Gabrielli, P., Marteel, A., Plane, J. M. C., Planchon, F. A. M., Gauchard, P.-A., Ferrari, C. P., Boutron, C. F., Adams, F. C., Hong, S., Cescon, P., and Barbante, C.: Atmospheric depletion of mercury over Antarctica during glacial periods, Nat. Geosci., 2, 505-508, doi:10.1038/ngeo549, 2009.

Johnson, K. P., Blum, J. D., Keeler, G. J., and Douglas, T. A.: Investigation of the deposition and emission of mercury in arctic snow during an atmospheric mercury depletion event, J. Geophys. Res., 113, D17304, doi:10.1029/2008JD009893, 2008.

Kain, J. S. and Fritsch, J. M.: A one-dimensional entraining/detraining plume model and its application in convective parameterization, J. Atmos. Sci., 47, 2784-2802, 1990.

King, M. D. and Simpson, W. R.: Extinction of UV radiation in Arctic snow at Alert, Canada $\left(82^{\circ} \mathrm{N}\right)$, J. Geophys. Res., 106, 1249912507, 2001.
Kirk, J. L., St. Louis, V. L., and Sharp, M. J.: Rapid reduction and emission of mercury deposited into snowpacks during atmospheric mercury depletion events at Churchill, Manitoba, Canada, Environ. Sci. Technol., 40, 7590-7596, 2006.

Krnavek, L., Simpson, W. R., Carlson, D., Domine, F., Douglas, T. A., and Sturm, M.: The chemical composition of surface snow in the Arctic: Examining marine, terrestrial, and atmospheric influences. Atmos. Environ., 50, 349-359, doi:10.1016/j.atmosenv.2011.11.003, 2012.

Kuhn, M.: The nutrient cycle through snow and ice, a review, Aquat Sci., 63, 150-167, 2001.

Lahoutifard, N., Sparling, M., and Lean, D.: Total and methyl mercury patterns in Arctic snow during springtime at Resolute, Nunavut, Canada, Atmos. Environ., 39, 7597-7606, 2005.

Lahoutifard, N., Poissant, L., and Scott, S. L.: Scavenging of gaseous mercury by acidic snow at Kuujjuarapik, Northern Québec, Sci. Total Environ., 355, 118-126, 2006.

Lalonde, J. D., Poulain, A. J., and Amyot, M.: The role of mercury redox reactions in snow on snow-to-air mercury transfer, Environ. Sci. Technol., 36, 174-178, 2002.

Lalonde, J. D., Amyot, M., Doyon, M.-R., and Auclair, J.-C. : Photo-induced $\mathrm{Hg}(\mathrm{II})$ reduction in snow from the remote and temperate Experimental lakes Area (Ontario, Canada), J. Geophys. Res., 108, 4200, doi:10.1029/2001JD001534, 2003.

Lamborg, C. H., Fitzgerald, W. F., Vandal, G. M., and Rolfhus, K. R.: Atmospheric mercury in northern Wisconsin: sources and species, Water Air Soil Poll., 80, 189-198, 1995.

Larose, C., Dommergue, A., De Angelis, M., Cossa, D., Averty, B., Marusczak, N., Soumis, N., Schneider, D., and Ferrari, C.: Springtime changes in snow chemistry lead to new insights into mercury methylation in the Arctic, Geochim. Cosmochim. Ac., 74, 6263-6275, doi:10.1016/j.gca.2010.08.043, 2010.

Leitch, D. R., Carrie, J., Lean, D., Macdonald, R. W., Stern, G. A., and Wang, F.: The delivery of mercury to the Beaufort Sea of the Arctic Ocean by the Mackenzie River, Sci. Total Environ., 373, 178-195, 2007.

Lin, C.-J., Pongprueksa, P., Lindberg, S. E., Pehkonen, S. O., Byun, D., and Jang, C.: Scientific uncertainties in atmospheric mercury models I: Model science evaluation, Atmos. Environ., 40, 29112928, 2006.

Lindberg, S. E., Brooks, S., Lin, C-J., Scott, K., Meyers, T., Chambers, L., Landis, M., and Stevens, R.: Formation of reactive gaseous mercury in the Arctic: Evidence of oxidation of $\mathrm{Hg}^{0}$ to gas-phase $\mathrm{Hg}$-II compounds after Arctic sunrise, Water Air Soil Poll.: Focus, 1, 295-302, 2001.

Lindberg, S. E., Brooks, S., Lin, C-J., Scott, K. J., Landis, M. S., Stevens, R. K., Goodsite, M., and Richter, A.: Dynamic oxidation of gaseous mercury in the Arctic troposphere at Polar Sunrise, Environ. Sci. Technol., 36, 1245-1256, 2002.

Loewen, M., Kang, S., Armstrong, D., Zhang, Q., Tomy, G., and Wang, F.: Atmospheric transport of mercury to the Tibetan Plateau, Environ. Sci. Technol., 41, 7632-7638, 2007.

Loseto, L. L., Lean, D. R. S., and Siciliano, S. D.: Snowmelt sources of methylmercury to High Arctic ecosystems, Environ. Sci. Technol., 38, 3004-3010, 2004.

Loux, N. T.: Monitoring cyclical air/water elemental mercury exchange, J. Environ. Monit., 3, 43-48, doi:10.1039/b005545j, 2001 . 
Lu, J. Y., Schroeder, W. H., Barrie, L. A., Steffen, A., Welch, H. E., Martin, K., Lockhart, L., Hunt, R. V., Boila, G., and Richter, A.: Magnification of atmospheric mercury deposition to polar regions in springtime: the link to tropospheric ozone depletion chemistry, Geophys. Res. Lett., 28, 3219-3222, 2001.

Macdonald, R. W., Harner, T., and Fyfe, J.: Recent climate change in the Arctic and its impact on contaminant pathways and interpretation of temporal trend data, Sci. Total Environ., 342, 5-86, doi:10.1016/j.scitotenv.2004.12.059, 2005.

Mann, J. L., Long, S. E., Shuman, C. A., and Kelly, W. R.: Determination of mercury content in a shallow firn core from Greenland by isotope dilution inductively coupled plasma mass spectrometry, Water Air Soil Poll., 163, 19-32, 2005.

Mason, R.: Mercury emissions from natural processes and their importance in the global mercury cycle, in Mercury fate and transport in the global atmosphere, 173-191, Springer USA, 2009.

Mason, R. P. and Fitzgerald, W. F.: The distribution and biogeochemical cycling of mercury in the equatorial Pacific Ocean, Deep-Sea Res. Pt. 1, 40, 1897-1924, 1993.

Matlab: R2011b Documentation: Statistics Toolbox for Matlab, The Mathworks, Inc., Natick, MA, USA, available at: http://www. mathworks.com/help/releases/R2011b/toolbox/stats/, 2011.

Mitchell, C. P. J., Branfireun, B. A., and Kolka, R. K.: Assessing sulfate and carbon controls on net methylmercury production in peatlands: An in situ mesocosm approach, Appl. Geochem., 23, 503-518, 2008a.

Mitchell, C. P. J., Branfireun, B. A., and Kolka, R. K.: Total mercury and methylmercury dynamics in upland-peatland watersheds during snowmelt, Biogeochemistry, 90, 225-241, doi:10.1007/s10533-008-9246-z, 2008b.

Mizukami, N. and Perica, S.: Spatiotemporal characteristics of snowpack density in the mountainous regions of the western United States, J. Hydrometeorol., 9, 1416-1426, 2008.

Monperrus, M., Tessier, E., Amouroux, D., Leynaert, A., Huonnic, P., and Donard, O. F. X.: Mercury methylation, demethylation and reduction rates in coastal and marine surface waters of the Mediterranean Sea, Mar. Chem., 107, 49-63, 2007.

Murozumi, M., Nakamura, S., and Yoshida, Y.: Compile data of chemical compositions in ice cores drilled at Mizuho Station, Mem. Natl. Inst. Polar Res., 10, 167-168, 1978.

Nelson, S. J., Johnson, K. B., Weathers, K. C., Loftin, C. S., Fernandez, I. J., Kahl, J. S., and Krabbenhoft, D. P.: A comparison of winter mercury accumulation at forested and no-canopy sites measured with different snow sampling techniques, Appl. Geochem., 23, 384-398, 2008.

Olivier, S., Schwikowsk, M., Brütsch, S., Eyrikh, S., Gäggeler, H. W., Lüthi, M., Papina, T., Saurer, M., Schotterer, U., Tobler, L., and Vogel, E.: Glaciochemical investigation of a ice core from Belukha glacier, Siberian Altai, Geophys. Res. Lett., 30, 2019, doi:10.1029/2003GL018290, 2003.

Outridge, P. M., Macdonald, R. W., Wang, F., Stern, G. A., and Dastoor, A. P.: A mass balance inventory of mercury in the Arctic Ocean, Environ. Chem, 5, 89-111, doi:10.1071/EN08002, 2008.

Pacyna, E. G., Pacyna, J. M., Sundseth, K., Munthe, J., Kindbom, K., Wilson, S., Steenhuisen, F., Maxson, P.: Global emission of mercury to the atmosphere from anthropogenic sources in 2005 and projections to 2020, Atmos. Environ. 44, 2487-2499, doi:10.1016/j.atmosenv.2009.06.009, 2010.
Poissant, L., Amyot, M., Pilote, M., and Lean, D.: Mercury water-air exchange over the upper St. Lawrence River and Lake Ontario, Environ. Sci. Technol., 34, 3069-3078, doi:10.1021/es990719a, 2000.

Poulain, A. J., Lalonde, J. D., Amyot, M., Shead, J. A., Raofie, F., and Ariya, P. A.: Redox transformations of mercury in an Arctic snowpack at springtime, Atmos. Environ., 38, 6763-6774, 2004.

Poulain, A. J., Garcia, E., Amyot, M., Campbell, P. G. C., and Ariya, P. A.: Mercury distribution, partitioning and speciation in coastal vs. inland High Arctic snow, Geochim. Cosmochim. Ac., 71, 3419-3431, 2007a.

Poulain, A. J., Roy, V., and Amyot, M.: Influence of temperate mixed and deciduous tree covers on $\mathrm{Hg}$ concentrations and photoredox transformations in snow, Geochim. Cosmochim. Ac., 71, 2448-2462, 2007b.

Risch, M. R., Gay, D. A., Fowler, K. K., Keeler, G. J., Backus, S. M., Blanchard, P., Barres J. A., and Dvonch, J. T.: Spatial patterns and temporal trends in mercury concentrations, precipitation depths, and mercury wet deposition in the North American Great Lakes region, 2002-2008. Environ. Pollut.. 161, 261-271, doi:10.1016/j.envpol.2011.05.030, 2012.

Ryaboshapko, A., Bullock, R., Christensen, J., Cohen, M., Dastoor, A., Ilyin, I., Petersen, G., Syrakov, D., Artz, R., Davignon, D., Draxler, R., and Munthe, J.: Intercomparison study of atmospheric mercury models: 1 . Comparison of models with shortterm measurements, Sci. Total Environ., 376, 228-240, 2007a.

Ryaboshapko, A., Bullock, R., Christensen, J., Cohen, M., Dastoor, A., Ilyin, I., Petersen G., Syrakov, D., Travnikov, O., Artz, R., Davignon, D., Draxler, R., Munthe, J., and Pacyna, J.: Intercomparison Study of Atmospheric Mercury Models: 2. Modelling results vs. long-term observations and comparison of country deposition budgets, Sci. Total Environ., 377, 319-333, 2007b.

Schroeder, W. H., Anlauf, K. G., Barrie, L. A., Lu, J. Y., Steffen, A., Schneeberger, D. R., and Berg, T.: Arctic springtime depletion of mercury, Nature, 394, 331-332, 1998.

Schuster, P. F., Krabbenhoft, D. P., Naftz, D. L., Cecil, L. D., Olson, M. K., Dewild, J. F., Susong, D. D., Green, J. R., and Abbott, M. L.: Atmospheric mercury deposition during the last 270 years: A glacial ice core record of natural and anthropogenic sources, Environ. Sci. Technol., 36, 2303-2310, 2002.

Seigneur, C., Abeck, H., Chia, G., Reinhard, M., Bloom, N. S. Prestbo, E., and Saxena, P.: Mercury adsorption to elemental carbon (soot) particles and atmospheric particulate matter, Atmos. Environ, 32, 2649-2657, 1998.

Sheppard, D. S., Patterson, J. E., and McAdam, M. K.: Mercury content of Antarctic ice and snow: Further results, Atmos. Environ., 25A, 1657-1660, 1991.

Sherman, L. S., Blum, J. D., Johnson, K. P., Keeler, G. J., Barres, J. A., and Douglas, T. A.: Mass-independent fractionation of mercury isotopes in Arctic snow driven by sunlight, Nat. Geosci., 3, 173-177, doi:10.1038/ngeo758, 2010.

Shetty, S. K., Lin, C.-J., Streets, D. G., and Jang, C.: Model estimate of mercury emission from natural sources in East Asia, Atmos. Environ., 42, 8674-8685, 2008.

Simpson, W. R., Carlson, D., Hönninger, G., Douglas, T. A., Sturm, M., Perovich, D., and Platt, U.: First-year sea-ice contact predicts bromine monoxide (BrO) levels at Barrow, Alaska better than potential frost flower contact, Atmos. Chem. Phys., 7, 621-627, doi:10.5194/acp-7-621-2007, 2007a. 
Simpson, W. R., von Glasow, R., Riedel, K., Anderson, P., Ariya, P., Bottenheim, J., Burrows, J., Carpenter, L. J., Frieß, U., Goodsite, M. E., Heard, D., Hutterli, M., Jacobi, H.-W., Kaleschke, L., Neff, B., Plane, J., Platt, U., Richter, A., Roscoe, H., Sander, R., Shepson, P., Sodeau, J., Steffen, A., Wagner, T., and Wolff, E.: Halogens and their role in polar boundary-layer ozone depletion, Atmos. Chem. Phys., 7, 4375-4418, doi:10.5194/acp-74375-2007, 2007b.

Skov, H., Christensen, J. H., Goodsite, M. E., Heidam, N. Z., Jensen, B., Wåhlin, P., and Geernaert, G.: Fate of elemental mercury in the Arctic during atmospheric mercury depletion episodes and the load of atmospheric mercury to the Arctic, Environ. Sci. Technol., 38, 2373-2382, 2004.

Slemr, F., Brunke, E.-G., Ebinghaus, R., and Kuss, J.: Worldwide trend of atmospheric mercury since 1995, Atmos. Chem. Phys., 11, 4779-4787, doi:10.5194/acp-11-4779-2011, 2011.

Snyder-Conn, E., Garbarino, J. R., Hoffman, G. L., and Oelkers, A.: Soluble trace elements and total mercury in Arctic Alaskan snow, Arctic, 50, 201-215, 1997.

Sommar, J., Wängberg, I., Berg, T., Gårdfeldt, K., Munthe, J., Richter, A., Urba, A., Wittrock, F., and Schroeder, W. H.: Circumpolar transport and air-surface exchange of atmospheric mercury at Ny-Ålesund $\left(79^{\circ} \mathrm{N}\right)$, Svalbard, spring 2002, Atmos. Chem. Phys., 7, 151-166, doi:10.5194/acp-7-151-2007, 2007.

Steen, A. O., Berg, T., Dastoor, A. P., Durnford, D. A., Hole, L. R., and Phaffhuber, K. A.: Dynamic exchange of gaseous elemental mercury during polar night and day, Atmos. Environ., 43, 5604$5610,2009$.

Steffen, A., Schroeder, W., Bottenheim, J., Narayan, J., and Fuentes, J. D.: Atmospheric mercury concentrations: measurements and profiles near snow and ice surfaces in the Canadian Arctic during Alert 2000, Atmos. Environ., 36, 2653-2661, 2002.

Steffen, A., Schroeder, W., Macdonald, R., Poissant, L., and Konoplev, A.: Mercury in the Arctic atmosphere: An analysis of eight years of measurements of GEM at Alert (Canada) and a comparison with observations at Amderma (Russia) and Kuujjuarapik (Canada), Sci. Total Environ., 342, 185-198, 2005.

Steffen, A., Douglas, T., Amyot, M., Ariya, P., Aspmo, K., Berg, T., Bottenheim, J., Brooks, S., Cobbett, F., Dastoor, A., Dommergue, A., Ebinghaus, R., Ferrari, C., Gardfeldt, K., Goodsite, M. E., Lean, D., Poulain, A. J., Scherz, C., Skov, H., Sommar, J., and Temme, C.: A synthesis of atmospheric mercury depletion event chemistry in the atmosphere and snow, Atmos. Chem. Phys., 8, 1445-1482, doi:10.5194/acp-8-1445-2008, 2008.

St. Louis, V. L., Rudd, J. W. M., Kelly, C. A., and Barrie, L. A.: Wet deposition of methyl mercury in northwestern Ontario compared to other geographic locations, Water Air Soil Poll., 80, 405-414, 1995.

St. Louis, V. L., Sharp, M. J., Steffen, A., May, A., Barker, J., Kirk, J. L., Kelly, D. J. A., Arnott, S. E., Keatley, B., and Smol, J. P.: Some sources and sinks of monomethyl and inorganic mercury on Ellesmere Island in the Canadian High Arctic, Environ. Sci. Technol., 39, 2686-2701, 2005.
St. Louis, V. L., Hintelmann, H., Graydon, J. A., Kirk, J. L., Barker, J., Dimock, B., Sharp, M. J., and Lehnherr, I.: Methylated mercury species in Canadian High Arctic marine surface waters and snowpacks, Environ. Sci. Technol., 41, 6433-6441, 2007.

Sturm, M. and Liston, G. E.: The snow cover on lakes of the Arctic Coastal Plain of Alaska, U.S.A, J. Glaciol., 49, 370-380, 2003.

Sunderland, E. M., Krabbenhoft, D. P., Moreau, J. W., Strode, S. A., and Landing, W. M.: Mercury sources, distribution, and bioavailability in the North Pacific Ocean: Insights from data and models, Global Biogeochem. Cy., 23, GB2010, doi:10.1029/2008GB003425, 2009.

Sundqvist, H.: A parameterization scheme for non-convective condensation including prediction of cloud water content, Q. J. Roy. Meteorol. Soc., 104, 677-690, 1978.

Susong, D. D., Abbott, M. L., and Krabbenhoft, D. P.: Mercury accumulation in snow on the Idaho National Engineering and Environmental laboratory and surrounding region, southeast Idaho, USA, Environ. Geol., 43, 357-363, 2003.

Travnikov, O.: Contribution of the intercontinental atmospheric transport to mercury pollution in the Northern Hemisphere, Atmos. Environ., 39, 7541-7548, 2005.

Travnikov, O., Lin, C.-J., Dastoor, A.: Global and Regional Modelling, edited by: Pirrone, N. and Keating, T., in: Hemispheric Transport of Air Pollution 2010, Part B: Mercury, Air Pollution Studies No. 18, Economic Commission for Europe, Geneva and United Nations, New York and Geneva, available at: http: //www.htap.org/, 2010.

Vandal, G. M., Fitzgerald, W. F., Boutron, C. F., and Candelone, J.P.: Variations in mercury deposition to Antarctica over the past 34,000 years, Nature, 362, 621-623, 1993.

Van Oostdam, J., Donaldson, S. G., Feeley, M., Arnold, D., Ayotte, P., Bondy, G., Chan, L., Dewaily, É., Furgal, C. M., Kuhnlein, H., Loring, E., Muckle, G., Myles, E., Receveur, O., Tracy, B., Gill, U., and Kalhok, S.: Human health implications of environmental contaminants in Arctic Canada: A review, Sci. Total Environ., 351-352, 165-246, 2005.

Wang, X.-p., Yao, T.-d., Wang, P.-1., Wei-Yang, and Tian, L.-d.: The recent deposition of persistent organic pollutants and mercury to the Dasuopu glacier, Mt. Xixiabangma, central Himalayas, Sci. Total. Environ., 394, 134-143, 2008.

Weiss, H. V., Herron, M. M., and Langway Jr., C. C.: Natural enrichments of elements in snow, Nature, 274, 352-353, 1978.

Witherow, R. A. and Lyons, W. B.: Mercury deposition in a Polar Desert ecosystem, Environ. Sci. Technol., 42, 4710-4716, 2008.

Yue, W., Meneveau, C., Parlange, M. B., Zhu, W., Kang, H. S., and Katz, J.: Turbulent kinetic energy budgets in a model canopy: comparisons between LES and wind-tunnel experiments, Environ. Fluid Mech., 8, 73-95, 2008.

Zhao, T. L., Gong, S. L., Bottenheim, J. W., McConnell, J. C., Sander, R., Kaleschke, L., Richter, A., Kerkweg, A., Toyota, K., and Barrie, L. A.: A three-dimensional model study on the production of $\mathrm{BrO}$ and Arctic boundary layer ozone depletion, J. Geophys. Res., 113, D24304, doi:10.1029/2008JD010631, 2008. 